\title{
Assessing the Effects of Microphysical Scheme on Convective and Stratiform Characteristics in a Mei-Yu Rainfall Combining WRF Simulation and Field Campaign Observations
}

\author{
Lin Liu $\mathbb{D},{ }^{1,2}$ Chunze Lin $\mathbb{D}^{1},{ }^{1}$ Yongqing Bai, ${ }^{1}$ and Dengxin $\mathrm{He}^{1}$ \\ ${ }^{1}$ Hubei Key Laboratory for Heavy Rain Monitoring and Warning Research, Institute of Heavy Rain, \\ China Meteorological Administration, Wuhan 430205, China \\ ${ }^{2}$ School of Atmospheric Sciences and Key Laboratory of Mesoscale Severe Weather, Ministry of Education, Nanjing University, \\ Nanjing 210023, China \\ Correspondence should be addressed to Chunze Lin; linchunze@whihr.com.cn
}

Received 5 October 2019; Revised 15 December 2019; Accepted 22 January 2020; Published 9 March 2020

Academic Editor: Harry D. Kambezidis

Copyright ( 92020 Lin Liu et al. This is an open access article distributed under the Creative Commons Attribution License, which permits unrestricted use, distribution, and reproduction in any medium, provided the original work is properly cited.

\begin{abstract}
Microphysics parameterization becomes increasingly important as the model grid spacing increases toward convection-resolving scales. Using observations from a field campaign for Mei-Yu rainfall in China, four bulk cloud microphysics schemes in the Weather Research and Forecasting (WRF) model were evaluated with respect to their ability to simulate precipitation, structure, and cloud microphysical properties over convective and stratiform regimes. These are the Thompson (THOM), Morrison graupel/ hail (MOR_G/H), Stony Brook University (SBU_YLIN), and WRF double-moment six-class microphysics graupel/hail (WDM6_G/H). All schemes were able to predict the rain band but underestimated the total precipitation by $23 \%-35 \%$. This is mainly attributed to the underestimation of stratiform precipitation and overestimation of convective rain. For the vertical distribution of radar reflectivity, many problems remain, such as lower reflectivity values aloft in both convective and stratiform regions and higher reflectivity values at middle level. Each bulk scheme has its advantages and shortcomings for different cloud regimes. Overall, the discrepancies between model output and observations mostly exist in the midlevel to upper level, which results from the inability of the model to accurately represent the particle size distribution, ice processes, and storm dynamics. Further observations from major field campaigns and more detailed evaluation are still necessary.
\end{abstract}

\section{Introduction}

The representation of microphysics is of substantial importance in numerical weather prediction (NWP) models because it controls the distributions of latent heating and cooling and condensate loading that influences the dynamics $[1,2]$. With the increases of computing power and NWP technology, more accurate and detailed descriptions of cloud microphysical processes are proposed and the trend has been toward prognostically calculating hydrometeor types and sizes explicitly [3-8]. However, these microphysical schemes have their own advantages in different types of cloud and weather system. Extensive and detailed validations for existing schemes are therefore needed to constrain and reduce uncertainties for different cloud types and regions.
Obvious discrepancies between models and observations are found by previous studies, such as smaller stratiform areal coverage, weaker precipitation $[9,10]$, and heavier precipitation from convective regions [11] in simulated storms. A recent trend in evaluating NWP models is to use remote sensing datasets such as satellites [12-14], radars $[15,16]$, and cloud-aerosol lidar $[17,18]$. These active sensors makes it possible to evaluate the three-dimensional structure of clouds and precipitation [19], and in particular, the simulated and observational reflectivity allows one to more easily see detailed meso- and storm-scale structures forecasted by finer-resolution NWP models [20, 21].

Parameterizing microphysics remains challenging because of fundamental uncertainty in the underlying microphysical processes, especially for ice [15]. Therefore, more 
hydrometeor variables need to be evaluated in addition to the macrophysical quantities just like accumulated rainfall and cloud coverage which are evaluated in previous research. Johnson et al. [22] used the observed polarimetric radar variables to evaluate the microphysics schemes in the ensemble forecasts, and they found that a hail-like rimed-ice category may be necessary to reproduce the observed hail signature. Remillard et al. [23] used cloud radar doppler spectra to evaluate stratocumulus drizzle size distributions in large-eddy simulations with size-resolved microphysics. Detailed observations from field campaigns which can reflect macro- and microphysical characteristics are also used. Naeger et al. [24] evaluated several bulk microphysical parameterizations in combination with observations from a cold season precipitation experiment of an intense warm frontal band. Taufour et al. [25] used the airborne in situ measurements and dual-polarization radar variables to evaluate a two-moment scheme. They found that improving the hydrometeor representation, focusing especially on the description of the particle size distributions for different water species, is a good way to improve microphysical scheme.

Utilizing multisource datasets from radar and field campaign to evaluate the cloud microphysical schemes has only recently begun in China. With the increases in local severe weather activities, the need for more accurate weather information has become increasingly crucial especially for Yangtze River basin where extreme precipitation occurs frequently during Mei-Yu season. Mei-Yu is one of the most significant events for the hydrological cycle in the East Asia monsoon region [26], which produces a large amount of flood disasters and substantial economic losses in the Yangtze-Huai River Valleys [27]. During Mei-Yu season, a quasi-stationary front, known as the Mei-Yu front, is formed and extends from eastern China to southern Japan [28]. At any given time, Mei-Yu front is associated with the presence of an elongated cloud band, which is usually a mixture of deep convective clouds and stratiform clouds [10]. Different microphysical and thermodynamic features are observed in two cloud regimes. In convective regions, the growth of ice is dominated by riming, whereas in stratiform regions, deposition and aggregation are the primary mechanisms [29]. The resultant latent heating profiles are quite different for the two regions [30, 31].

To provide a much needed data source concerning the formation-dissipation processes of mesoscale convective system (MCS) during the Mei-Yu season, a field campaign entitled the "Investigative Monsoon Frontal Rainfall Experiment (IMFRE) 2018” was conducted from 10 June 2018 to 10 July 2018 in the middle reaches of the Yangtze River (MRYR). The purpose of this study is to investigate the impacts of bulk cloud microphysics schemes on the simulation of different cloud regimes (stratiform and convective clouds) along the Mei-Yu front using observations from the IMFRE 2018. We will examine the differences in the evolution, horizontal, and vertical structure of MCS and determine the strengths and weaknesses of different microphysics schemes for Mei-Yu rainfall. Furthermore, the cloud microphysical properties from C-band dual- polarization doppler weather radar (C-POL) are also evaluated. The remainder of this paper is organized as follows. Section 2.2 describes the datasets used in this study. The methods and description of the case study are presented in Section 2. The results and discussions are presented in Section 3. Finally, the main findings of this study are summarized in Section 4.

\section{Data and Methods}

2.1. Precipitation Data and Reanalysis. A precipitation product [32], based on the rain gauge precipitation from automatic weather stations in China and the Climate Prediction Center morphing technique (CMORPH) precipitation [33], was used in this study. This product has a $0.1^{\circ} \times 0.1^{\circ}$ spatial resolution with hourly temporal resolution. What is more, large-scale air flow and thermodynamic conditions of Mei-Yu front are analyzed with the hourly ERA-5 reanalysis [34] in uniform grid of $0.25^{\circ} \times 0.25^{\circ}$, which is the latest and fifth generation of European reanalysis produced by the European Center for Medium-Range Weather Forecasts (ECMWF). The ERA-5 reanalysis was also used as model initial and lateral boundary conditions.

2.2. Datasets from Field Campaign. Various datasets have been collected to study the mechanism of MCS during Mei$\mathrm{Yu}$ season from the field campaign of IMFRE 2018. Threedimensional structures and microphysical properties of MCS measured by IMFRE provide critical observations to examine the impacts of different bulk schemes on cloud microphysics and precipitation. The red dot (Figure 1(a)) represents the Xianning site of the field campaign, where convective systems can easily start and develop because of the impact of mesoscale topography, primarily influenced by the Mufu Mountain to the southeast of Xianning.

The primary instruments used in this study include the China New Generation Weather Radar (CINRAD) and C-POL. In the studying area, there are $15 \mathrm{~S}$-band operational Doppler radars (the black circles in Figure 1(a)) operating at $10 \mathrm{~cm}$ wavelength and providing 9 unique elevation scans every 6 minutes). The reflectivity datasets underwent critical quality control $[35,36]$ and were gridded to $3 \mathrm{~km}$ horizontally and $0.5 \mathrm{~km}$ vertically in an attempt to make a comparison with model simulations. C-POL is located in Xianning site (the red dot in Figure 1(a)); the specifications of measurements from C-POL are shown in Table 1. The radar data are preprocessed by a group of algorithms [37] so as to provide hydrometeor categories. The algorithms include corrections of system biases of reflectivity and differential reflectivity, suppression of ground clutter and anomalous echoes, and filtering of differential phase shift.

2.3. Model Setup and Experiments Design. To investigate the effects of microphysical schemes on convective and stratiform characteristics in a Mei-Yu front storm, several numerical experiments were performed with the Weather Research and Forecasting (WRF version 3.6.1) model, a nonhydrostatic, compressible, three-dimensional atmospheric model. The 


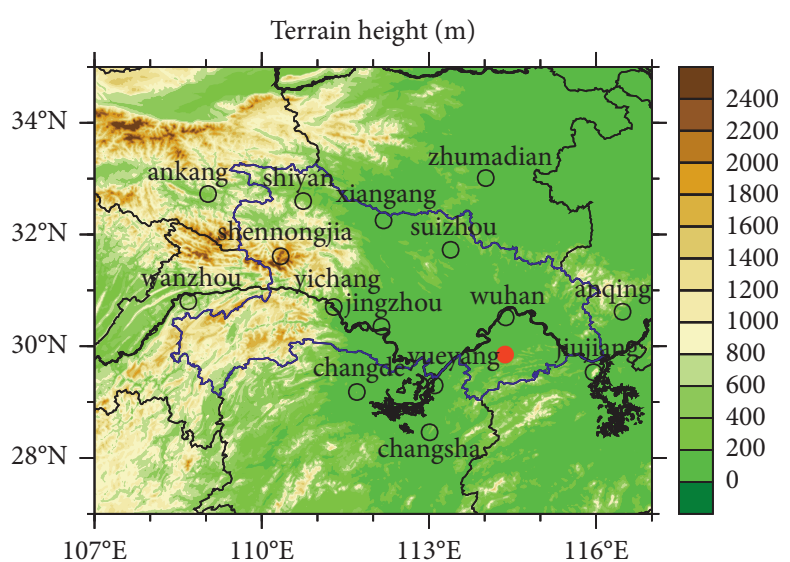

(a)

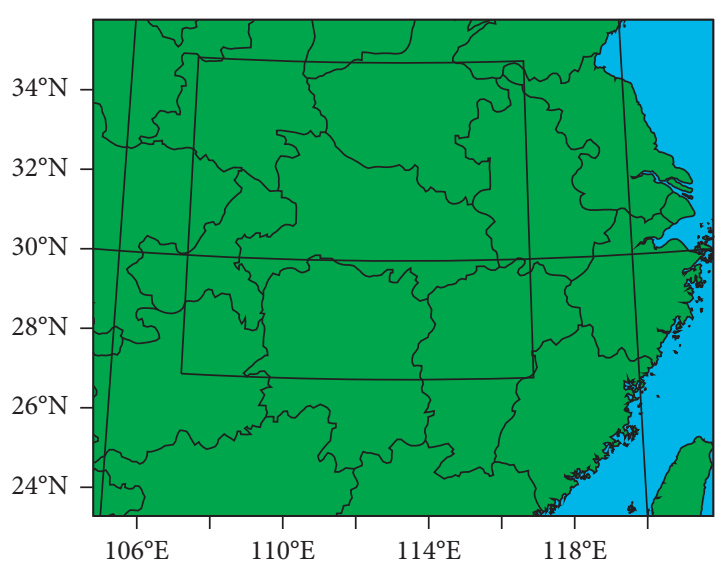

(b)

FIGURE 1: (a) Distribution of 15 S-band operational Doppler radars (circles), and the campaign field site of Xianning station (red dot), as well as Yangtze River (thick solid lines) and boundaries of provinces (thin solid lines); shadings represent the terrain height. Hubei Province is indicated by the blue line. (b) Simulation domain used in the WRF simulations; the black box represents the range of Figure 1(a) for domainaverage analysis in this study.

TABLE 1: Main specifications of the C-POL used in the IMFRE field campaign.

\begin{tabular}{lc}
\hline Main specifications & Parameter settings \\
\hline Antenna diameter & $3.2 \mathrm{~m}$ \\
Beam width & $1.4^{\circ}$ \\
Wavelength & $5.5 \mathrm{~cm}$ \\
Pulse length & $1.0 \mu \mathrm{s}$ \\
Peak power & $\geq 250 \mathrm{~kW}$ \\
Sensitivity in Z & $-15 \sim 70 \mathrm{dBZ}$ \\
Range resolution & $75,150 \mathrm{~m}$ \\
Temporal resolution & $1 \sim 6 \mathrm{~min}$ \\
\hline
\end{tabular}

simulation domain consisted of 560 by 530 grids with a horizontal resolution of $3 \mathrm{~km}$ (Figure 1(b)). There were 50 layers from surface to $50-\mathrm{hPa}$. All simulations started at 0600 UTC 29 June with 30-hour run. And the model outputs were saved at a 12 -min interval.

In this paper, four bulk microphysical schemes were tested in WRF to investigate their performance in simulating the structure and evolution of MCSs and cloud microphysics, with a focus on the convective-stratiform precipitation processes. The schemes are Thompson (THOM) scheme [6], the Morrison graupel/hail (MOR_G/H) scheme [7], the Stony Brook University microphysics scheme (SBU-YLIN) [38], and the WRF double-moment six-class microphysics (WDM6) graupel/hail (WDM6_G/H) scheme [8]. Each scheme is described briefly in Table 2 . Other physics parameterization schemes include the Yonsei University (YSU) planetary boundary layer (PBL) scheme [39], the Rapid Radiative Transfer Model for General Circulation Models (RRTMG) scheme for longwave radiation calculations [40], the Goddard shortwave scheme for shortwave radiation calculations [41], and the Noah land surface scheme [42].

2.4. Convective-Stratiform Partitioning Algorithm. In order to analyze the convective-stratiform precipitation processes in a Mei-Yu front storm, a partitioning algorithm, based on Steiner et al. [43], was used to separate areas of convection from stratiform regions for each synthesized radar volume. Several input parameters for the partitioning scheme are tuned to fit the midlatitude scenarios because the scheme is originally developed for tropical convection [44]. The partitioning algorithm is based on the $3 \mathrm{~km}$ horizontal radar reflectivity gradient, which is a background exceeding technique using a low-level 2D horizontal reflectivity field [45]. The algorithm has three steps. First, any grid points having reflectivities greater than $43 \mathrm{dBZ}$ are classified as convective, according to the Z-R relationship in midlatitudes [44]. Second, Reflectivity at each radar grid is compared to its background intensity, computed using the linearly averaged reflectivity with an 11-km radius centered on the grid. Any grid point that exceeds its background reflectivity by an intensity-dependent value is classified as convective. Last, for each grid point classified as convective by either of the two tests, an intensity-dependent radius of influence is used to assign an area around the point as convective. The rest of the echoes that exceed $10 \mathrm{dBZ}$ are classified as stratiform.

This algorithm is also suitable for the WRF-simulated radar reflectivity so that the model results are evaluated at the same metrics as the observations. WRF-simulated radar reflectivity is calculated assuming Rayleigh scattering following the approach of Smith [45], using the specified or predicted size distribution and particle-density parameters consistent with each scheme.

\section{Results and Discussion}

In this section, the simulations of the above four microphysical schemes are evaluated from rainfall among different cloud regimes, horizontal and vertical structure of MCS, and cloud microphysical properties, determining their strengths and weaknesses for Mei-Yu rainfall over the MRYR. 
TABLE 2: Characteristics of the four microphysical schemes used for the WRF simulations.

\begin{tabular}{|c|c|c|}
\hline Scheme (acronym) & $\begin{array}{c}\text { No. of } \\
\text { moments }\end{array}$ & Notes \\
\hline Thompson (THOM) & 2 & $\begin{array}{l}\text { The scheme prognoses the mass mixing ratios of cloud droplets, cloud ice, rain, } \\
\text { snow, and a hybrid graupel/hail category, plus the number mixing ratios of cloud ice } \\
\text { and rain }\end{array}$ \\
\hline Morrison graupel/hail (MOR_G/H) & 2 & $\begin{array}{l}\text { Explicit prediction of mass and number mixing ratios of rain, cloud ice, snow, and } \\
\text { graupel/hail and mass mixing ratio of cloud droplets }\end{array}$ \\
\hline $\begin{array}{l}\text { Stony Brook University } \\
\text { microphysics (SBU-YLIN) }\end{array}$ & 1 & $\begin{array}{c}\text { The scheme prognoses mass mixing ratios of cloud droplets, rain, cloud ice, and } \\
\text { precipitating ice }\end{array}$ \\
\hline $\begin{array}{l}\text { Double-moment six-class graupel/ } \\
\text { hail (WDM6_G/H) }\end{array}$ & 2 & $\begin{array}{l}\text { The scheme prognoses mass mixing ratios of cloud droplets, rain, cloud ice, snow, } \\
\text { and graupel and number mixing ratios of cloud droplets, rain, and cloud } \\
\text { condensation nuclei }\end{array}$ \\
\hline
\end{tabular}

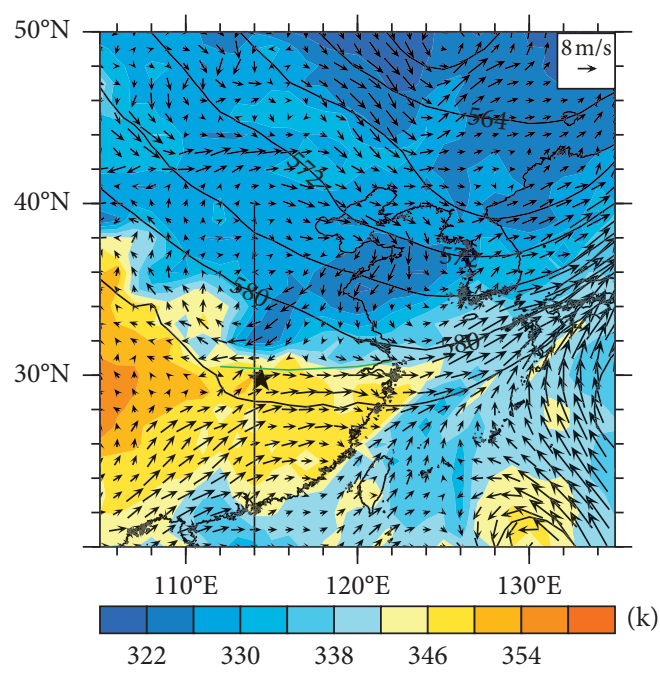

(a)

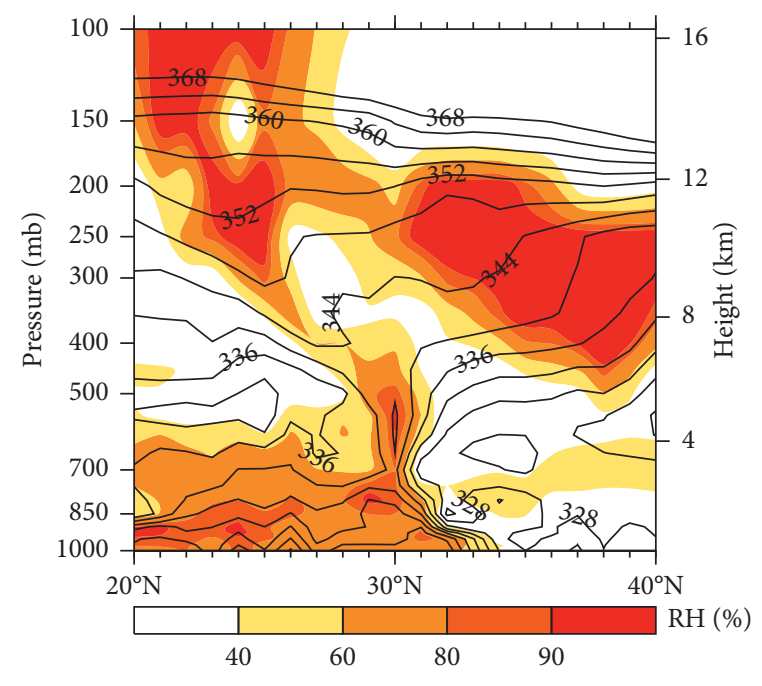

(b)

Figure 2: Large-scale air flow and thermodynamic conditions at 0000 UTC 30 June 2018 from ERA-5 reanalysis.(a) Horizontal wind vector (arrows) at $700 \mathrm{hPa}$, geopotential height at $500 \mathrm{hPa}$ (thick solid lines), and pseudo-equivalent potential temperature at $850 \mathrm{hPa}$ (shading). The green line in (a) indicates the winds shear line at $700 \mathrm{hPa}$. (b) Vertical cross sections along $114^{\circ} \mathrm{E}$ of pseudo-equivalent potential temperature (solid lines) and relative humidity (shading).

3.1. Case Description. During IMFRE field campaign 2018, a Mei-Yu front storm was initiated over the MRYR and lasted for about 19 hours from 1800 UTC 29 June to 1200 UTC 30 June. The large-scale meteorological conditions derived from ERA-5 reanalysis at 0000 UTC 30 June are presented in Figure 2. The field of air flow at $700-\mathrm{hPa}$ was characterized by a northeast-southwest oriented shear line formed at $29-30^{\circ} \mathrm{N}$ (the green line in Figure 2(a)). South of this shear line, there was a warm and moist southwesterly low-level jet (LLJ) extending from the South China Sea to the JiangHuai Basin. The large pseudo-equivalent potential temperature gradient at $850-\mathrm{hPa}$, which is often referred to as the location of Mei$\mathrm{Yu}$ front, is also near $30^{\circ} \mathrm{N}$. These large-scale weather conditions are typical features of Mei-Yu front rainstorm.

Figure 3 describes the life cycle of the Mei-Yu front rainstorm via the hourly radar reflectivity at $3 \mathrm{~km}$ from 0000 to 0800 UTC 30 June, 2018. During the developing stage (1800 UTC 29 June-0200 UTC 30 June), two small MCSs along the northwest-southeast oriented shear line formed and strengthened when moving eastward. At the mature stage (0300-0600 UTC 30 June), the two MCSs merged into one convective system and remained between 112 and $114^{\circ} \mathrm{E}$. After 0600 UTC 30 June, the MCSs weakened and gradually dissipated, while the stratiform region remained quite extensive until 0800 UTC 30 June.

The MCSs occurred along the Mei-Yu front, causing moderate precipitation in Central Hubei Province with northwest-southeast oriented rain bands and the rain center exceeded $100 \mathrm{~mm}$ adjacent to Xianning site (Figure 4(a)). As shown in Figure 5, rainfall mainly occurred during 0000-1200 UTC on 30 June precipitation and the peak occurred during 0400-0600 UTC on 30 June.

3.2. Evaluation of Convective-Stratiform Precipitation. In spite of minor location errors for the rainfall as compared with the observations, all simulations captured the distribution of northwest-southeast oriented rain bands (Figure 4). Thompson scheme (Figure 4(b)) simulates precipitation centers lager than $75 \mathrm{~mm}$ as a little bit 


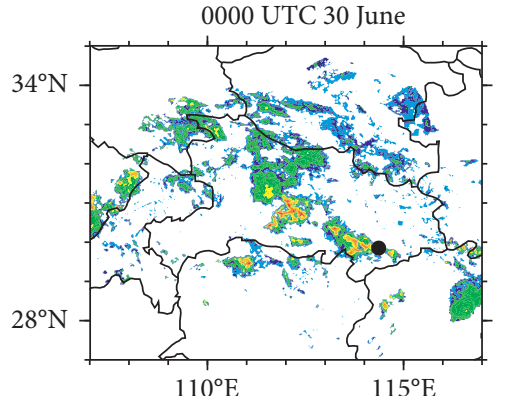

(a)

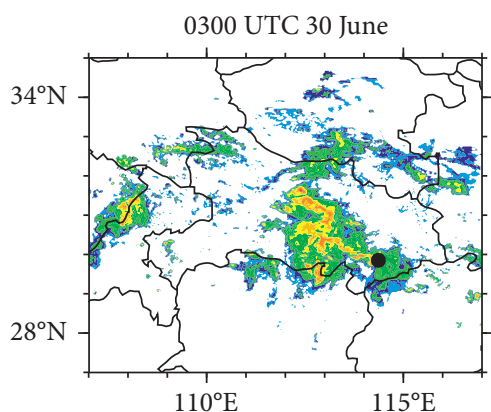

(d)

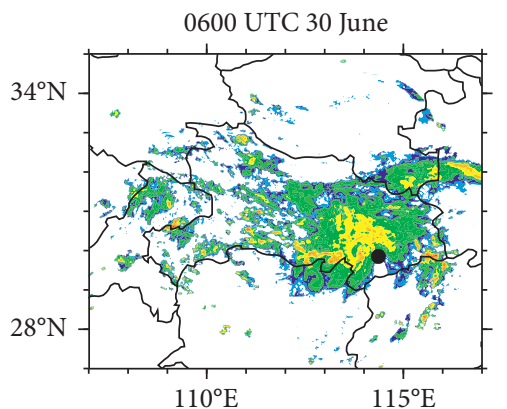

(g)

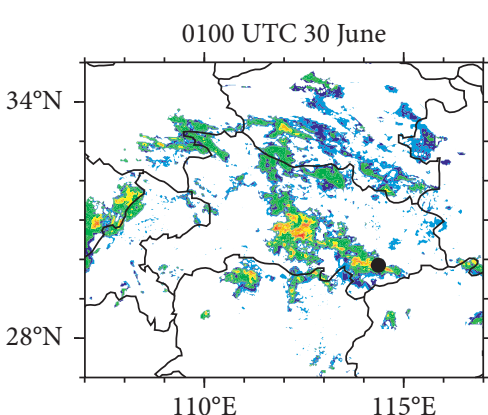

(b)

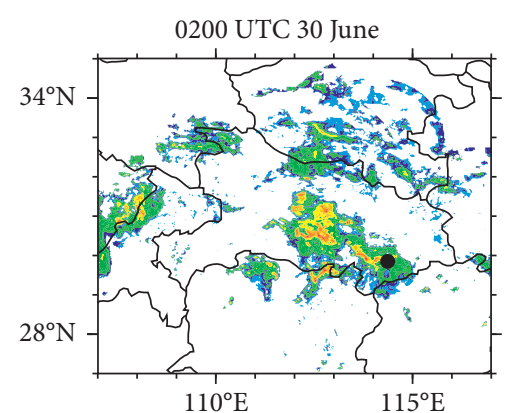

(c)

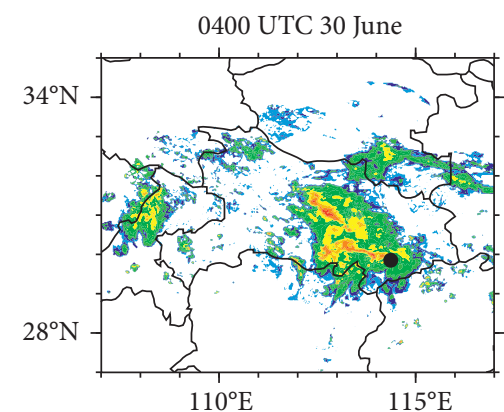

(e)

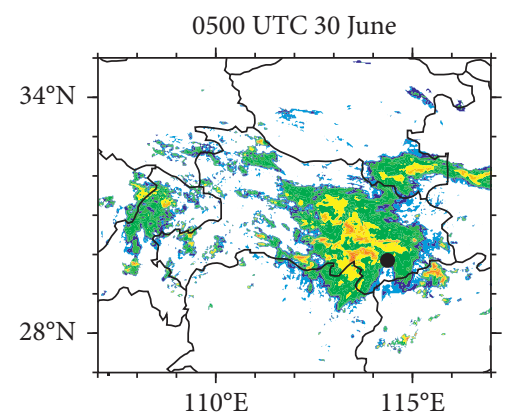

(f)

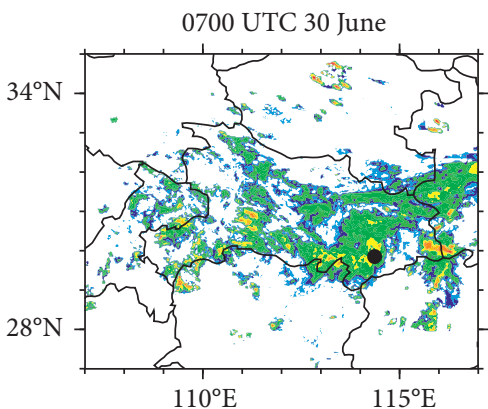

(h)

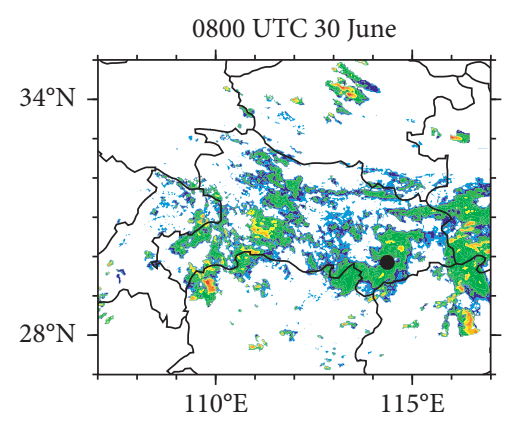

(i)

\begin{tabular}{|l|lll|l|l|l|l|l|l|l|l|}
\hline & & & & & & & & & & & \\
(dBZ)
\end{tabular}

FIGURE 3: Distributions of radar reflectivity (in dBZ) at $3 \mathrm{~km}$ altitude every 1 -hr based on ground-based radar measurements obtained from 0000 to 0800 UTC 30 June 2018. The black dot indicates Xianning site.

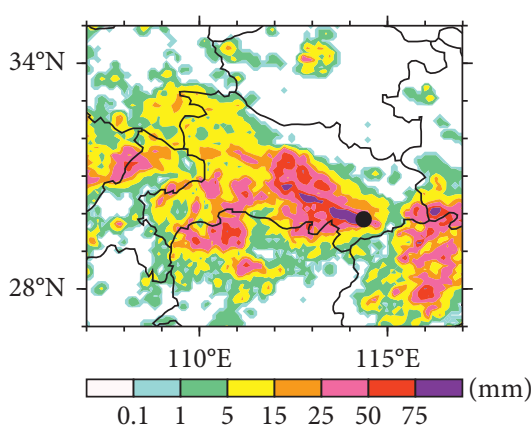

(a)

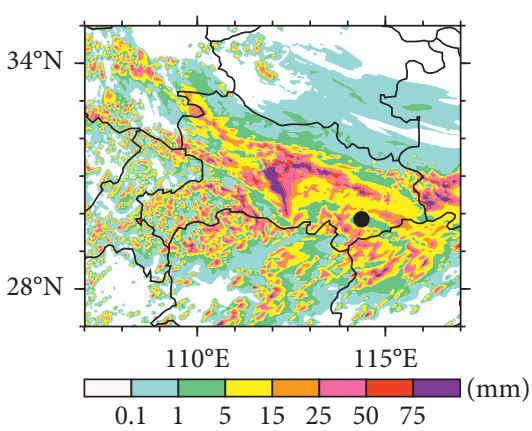

(b)

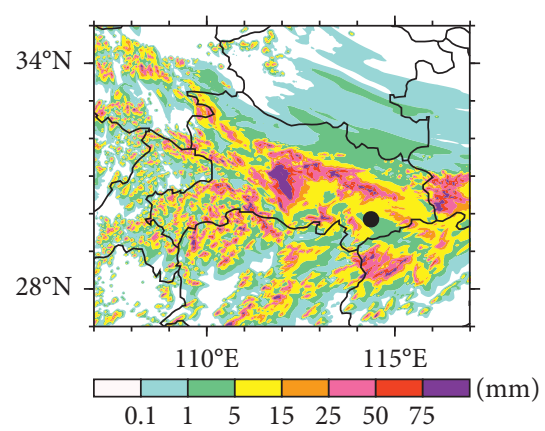

(c)

Figure 4: Continued. 


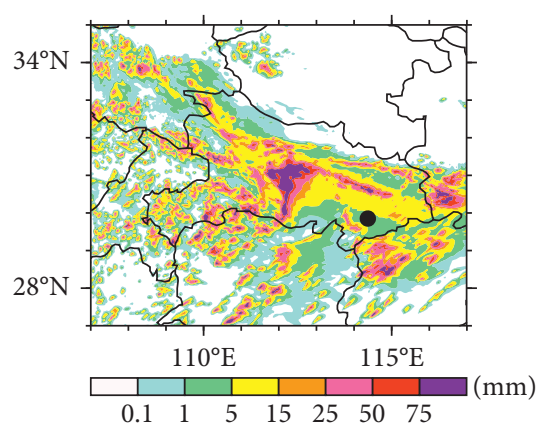

(d)

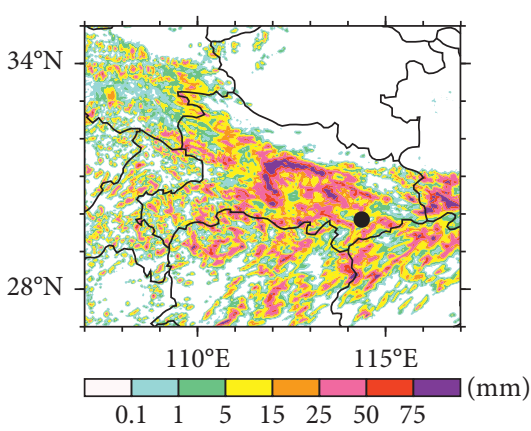

(e)

FIGURE 4: Longitude-latitude distribution of surface precipitation accumulated from 1800 UTC 29 June to 1200 UTC 30 June 2018 from (a) rain gauge observations and simulations of (b) THOM, (c) MOR_G/H, (d) SBU-YLIN, and (e) WDM6_G/H scheme.

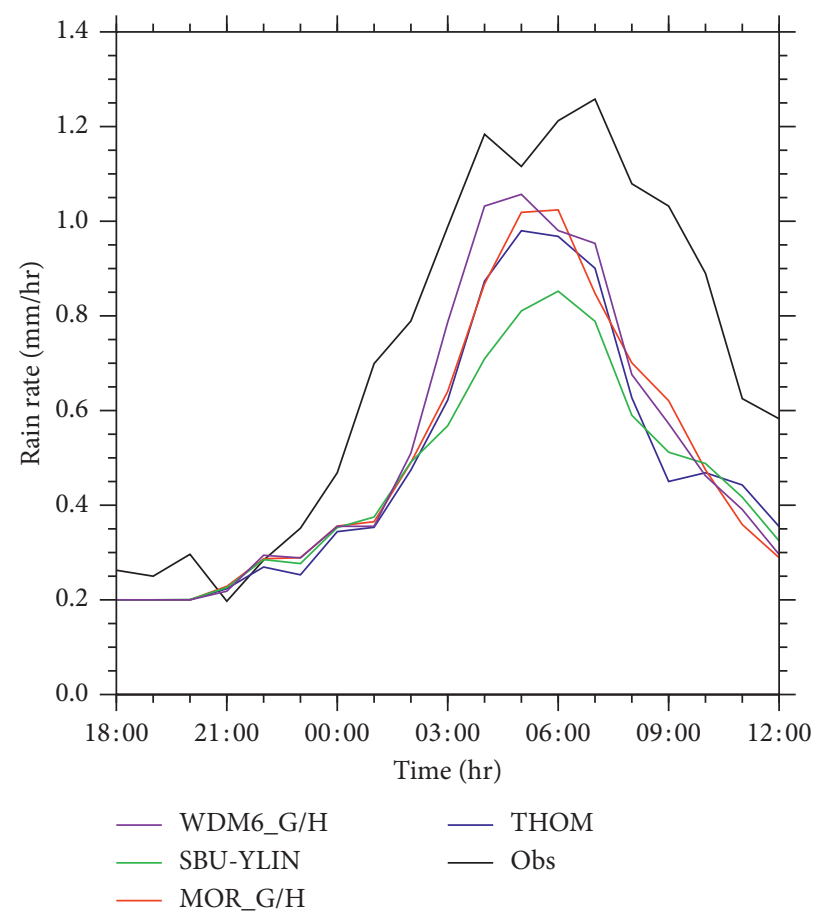

FIGURE 5: Hourly surface precipitation rate averaged within the region $\left(107-117^{\circ} \mathrm{E}, 27-35^{\circ} \mathrm{N}\right)$ from the observations (black solid curve) and the simulations of THOM (blue curve), MOR_G/H (red curve), SBU-YLIN (green curve), and WDM6_G/H (purple curve).

northwest with a larger scope, with the $15-50 \mathrm{~mm}$ centers being smaller than the observation (Figure 4(a)), and so do the Morrison (Figure 4(c)) and SBU-YLIN scheme (Figure $4(\mathrm{~d})$ ). The rain scopes less than $15 \mathrm{~mm}$ simulated by the first three schemes (Thompson, Morrison, and SBUYLIN scheme) are close to the observation. In contrast, the locations of heavy precipitation (more than $50 \mathrm{~mm}$ ) simulated by the WDM6_G/H scheme (Figure 4(e)) are scattered with a larger scope than the observation, while the rain scope less than $15 \mathrm{~mm}$ is smaller than the observation. To quantitatively evaluate the simulated precipitation, Figure 5 shows the time series of hourly surface rain rate from the observations and WRF simulations with 4 microphysics schemes. As shown, the tendencies of simulated curves are close to observations but all schemes underestimate the total mean precipitation by $23 \%-35 \%$. Total precipitation values from WDM6_G/H, THOM, and MOR_G/H scheme are more close to the observation than the SBU-YLIN scheme.

In order to evaluate the WRF-simulated MCS structure in those convective and stratiform regions, the classification algorithm used by Steiner et al. [43] has been applied to both radar observations and WRF simulations. Figure 6 shows the hourly rain rates which are averaged over the convective and stratiform regions from both observations and the WRF simulations. Compared with the mean observed convective rain rate $(4.43 \mathrm{~mm} / \mathrm{h})$, the first three simulations (Figures 6(b)-6(d)) overestimate the convective precipitation rate ranging from $4.57 \mathrm{~mm} / \mathrm{h}$ for the THOM scheme to $5.43 \mathrm{~mm} / \mathrm{h}$ for MOR_G/H. We also 


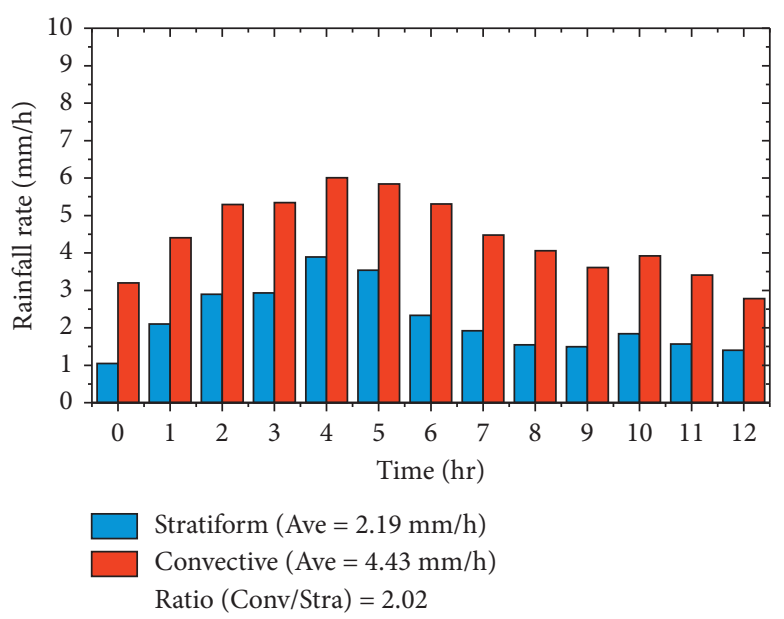

(a)

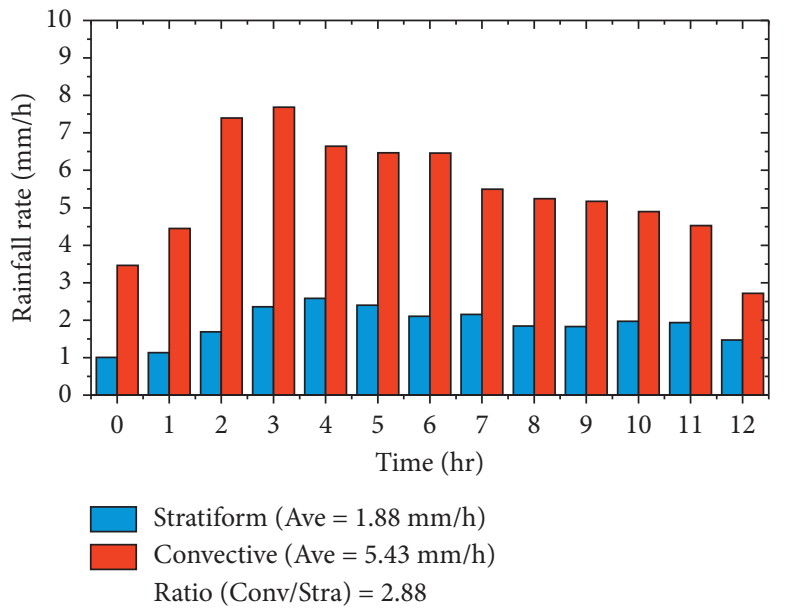

(c)

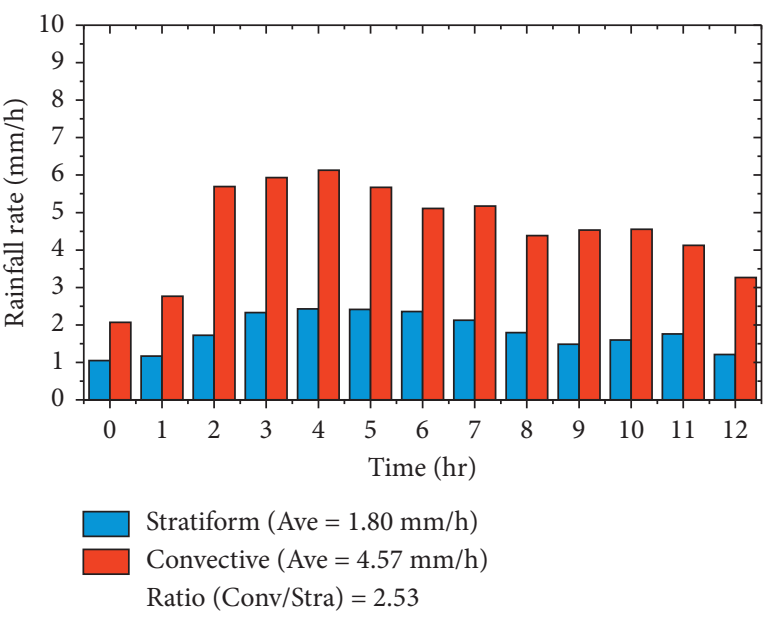

(b)

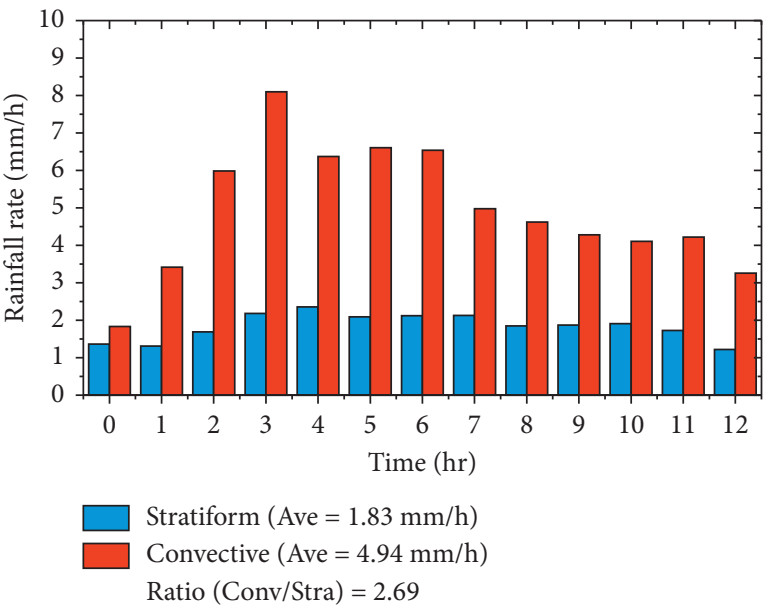

(d)

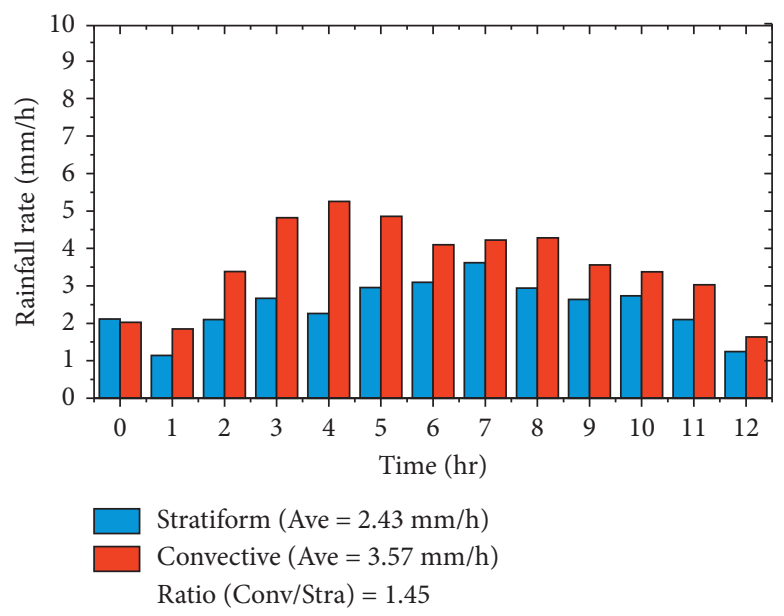

(e)

FIGURE 6: Hourly averaged precipitation rate over convective (red) and stratiform (blue) regions from (a) observations and (b) THOM, (c) MOR_G/H, (d) SBU-YLIN, and (e) WDM6_G/H scheme. The mean values in the upper right corner are the time- and domain-averaged rain rates over convective and stratiform regions during 00:00-12:00 UTC 30 June 2018.

found that the first three schemes have simulated less stratiform rainfall than the observation $(2.19 \mathrm{~mm} / \mathrm{h})$. As a result, the ratio of convective to stratiform precipitation is much higher than the observed one, especially in MOR_G/H and SBU-YLIN scheme. Most of the schemes underestimate the stratiform precipitation and 


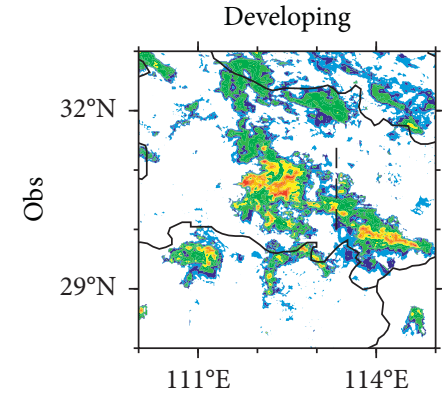

(a)

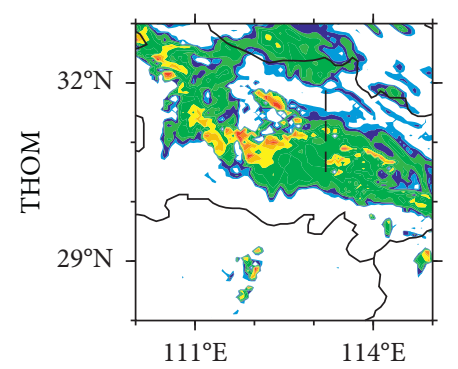

(d)

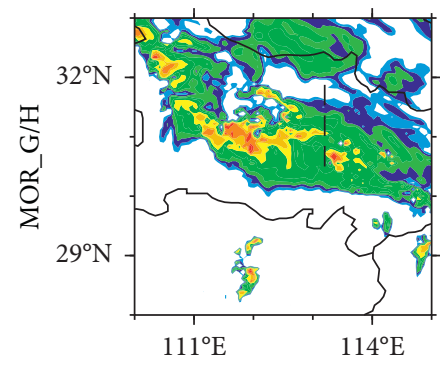

(g)

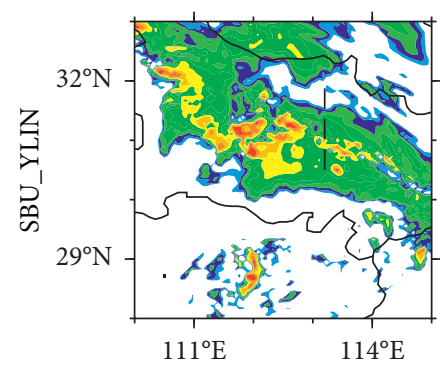

(j)

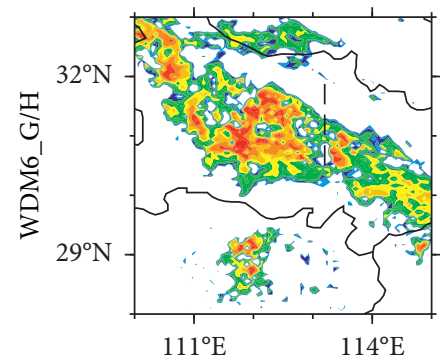

(m)

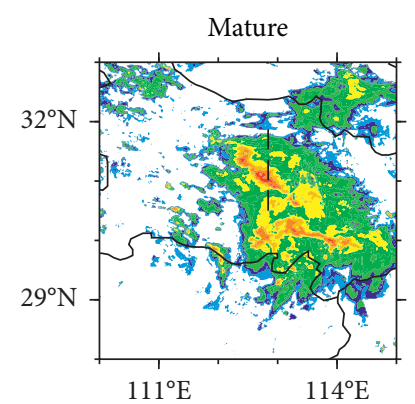

(b)

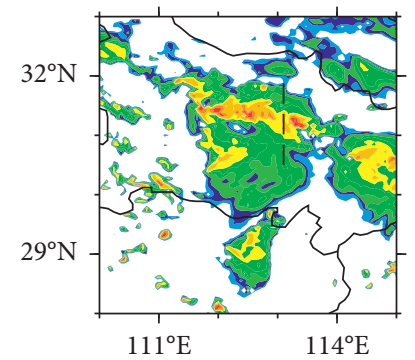

(e)

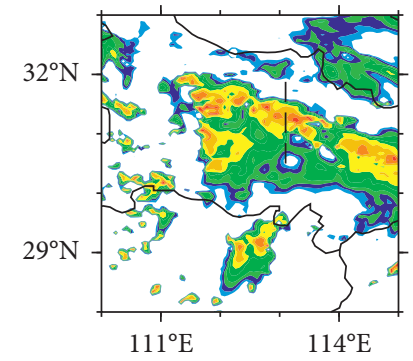

(h)

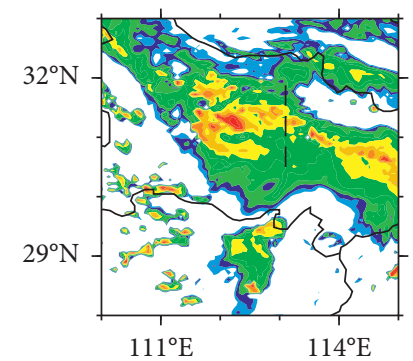

(k)

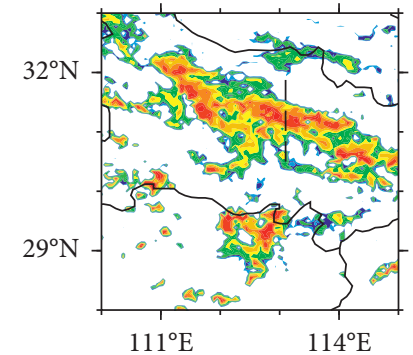

(n)

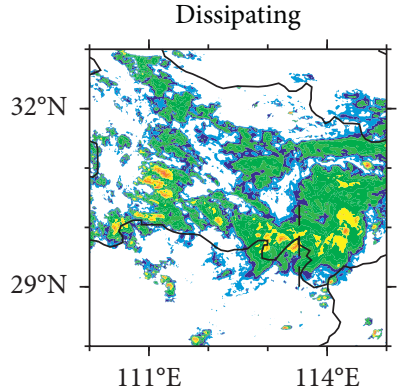

(c)

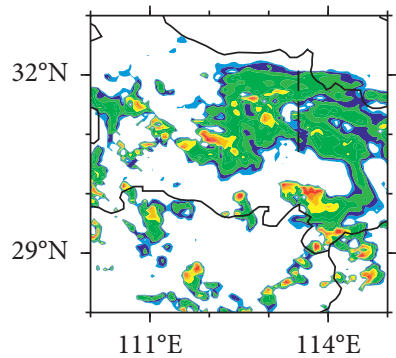

(f)

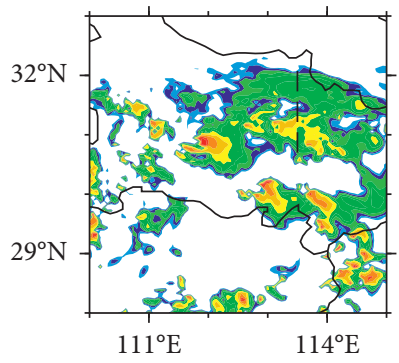

(i)

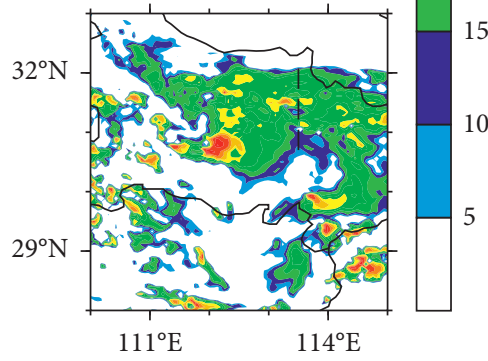

(1)

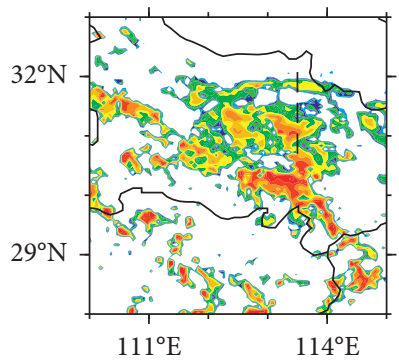

(o)

Figure 7: Comparisons of (a), (b), (c) radar reflectivity (Ze, dBZ) at $3 \mathrm{~km}$ and modeled radar reflectivity of (d), (e), (f) THOM; (g), (h), (i) MOR_G/H; (j), (k), (l) SBU-YLIN; and (m), (n), (o) WDM6_G/H during developing (the first column), mature (the second column), and dissipating (the third column) stage. The black lines are used to define the cross section in Figure 9. 


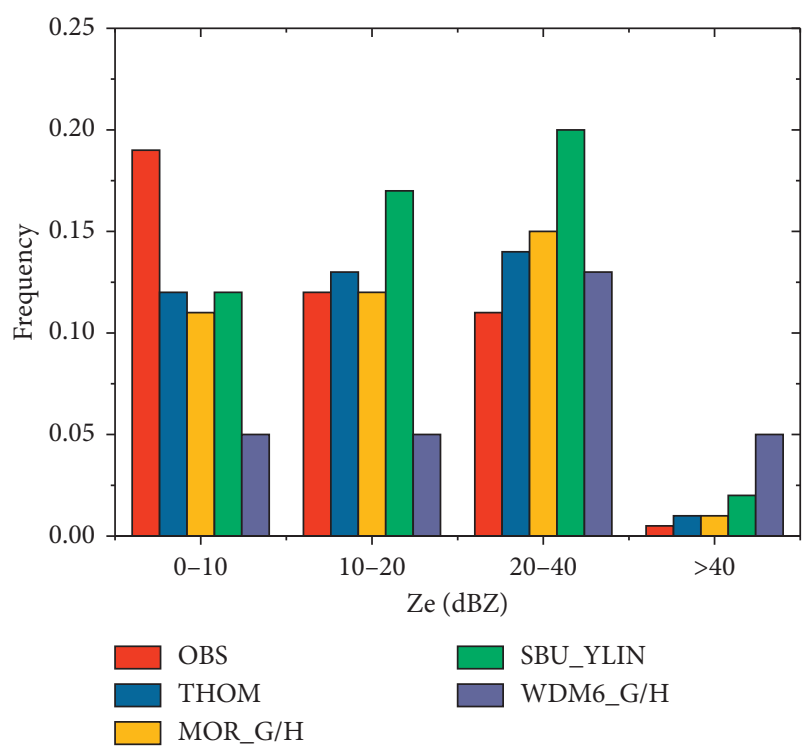

FIGURE 8: Comparisons of radar reflectivity (Ze, dBZ) frequency at $3 \mathrm{~km}$ altitudes from observations and simulations. The analysis domain is shown in Figure 1(a). The occurrence frequency is calculated by the number of grid points falling in each $\mathrm{Ze}$ range divided by the total number of the grid points of the analysis domain using output from 0000 UTC to 1200 UTC on 30 June 2018.

overestimate the convective rain except the WDM6_G/H scheme, which produces more stratiform precipitation.

\subsection{Horizontal and Vertical Structure of Mei-Yu Front} Rainstorm. To evaluate the horizontal distribution of simulated MCS, $3 \mathrm{~km}$ radar reflectivity $(\mathrm{Ze}, \mathrm{dBZ})$ at developing (0100 UTC), mature (0400 UTC), and dissipating (0700 UTC) stage are presented in Figure 7. THOM, MOR_G/H, and SBU-YLIN schemes capture the two smaller MCSs at the developing stage, although the MCSs location is a little bit northwest than the observations. At the mature stage, the two simulated MCSs are merged into one just like the radar observations, but there is a time delay in the three schemes. The simulated centers with large $\mathrm{Ze}(\mathrm{Ze}>40 \mathrm{dBZ})$ are also scatted by the WDM6_G/H scheme. At the dissipation stage, the WDM6_G/H simulations are much stronger than the observations and the others are close to observations. Figure 8 shows the comparisons of Ze frequency at $3 \mathrm{~km}$ altitudes from observations and simulations to further examine the horizontal distribution of Ze. Compared to the observations, all schemes dramatically underestimate the occurrence frequency of lower $\mathrm{Ze}(0<\mathrm{Ze}<10 \mathrm{dBZ})$ but overestimate the occurrence frequency of higher $\mathrm{Ze}$ (Ze > $20 \mathrm{dBZ}$ ). Except for WDM6_G/H, the other schemes also overestimate the frequency of medium $\mathrm{Ze}$ $(10<\mathrm{Ze}<20 \mathrm{dBZ})$. In general, all schemes underestimate the occurrence frequency of lower $\mathrm{Ze}$ but overestimate frequency of higher Ze, especially for the WDM6_G/H scheme.

We further examined the vertical structure of MCS between the observations and simulations. The cross sections of $\mathrm{Ze}$ indicated by a black line in Figure 7 are chosen to study the evolution of the vertical structure (Figure 9). It can be found that the large reflectivity ( $\mathrm{Ze}>40 \mathrm{dBZ}$ ) within the deep convective cores from radar extended to about $6 \mathrm{~km}$ at the developing stage. The simulated heights of deep convective cores are close to observations except for MOR_G/H scheme with the large reflectivity extended to about $9 \mathrm{~km}$. At the mature stage, deep convective cores of THOM and WDM6_G/H schemes extended to about $12 \mathrm{~km}$ which is almost the same distance that occurred in radar observations. However, all simulations underestimate radar reflectivity in the stratiform region at heights of $9-13 \mathrm{~km}$ during the whole lifetime of MCSs.

The Contoured Frequency by Altitude Diagrams (CFADs) of reflectivity are shown in Figure 10 from both radar observations and WRF simulations for stratiform and convective cloud, which are produced from the reflectivity volume at 12 -min intervals from 03 to 05 UTC on 30 June 2018. This period corresponds exactly to the mature stage of MCS. Discrepancies in the reflectivity distribution characteristics between simulations and observations are obvious. For stratiform cloud, the simulated maximum frequency of Ze (except SBU-YLIN) at lower levels is much smaller than the observations, which are located around $25-30 \mathrm{dBZ}$ and $10 \mathrm{dBZ}$. Near $6 \mathrm{~km}$, the observed maximum frequency of $\mathrm{Ze}$ is located around $20-30 \mathrm{dBZ}$ and decreases with height. The simulations of THOM and MOR_G/H scheme are close to this observation. The simulated $\mathrm{Ze}(\mathrm{Ze}>10 \mathrm{dBZ})$ frequency from all schemes at upper levels $(10-14 \mathrm{~km})$ is smaller than the observations. For convective cloud, the observed maximum frequency of $\mathrm{Ze}$ at middle and lower levels $(0-6 \mathrm{~km})$ is located around 35-40 dBZ, and the simulations of THOM and SBU-YLIN are as much as the observations. The simulated frequency of Ze around 30-50 dBZ from MOR_G/H scheme is stronger than other schemes. Simulated frequency of Ze around 20-35 dBZ above $6 \mathrm{~km}$ is much weaker than the observations. This kind of vertical distributions of the simulations may cause the simulated MCS to be lower than the observed.

3.4. Microphysical Properties of Hydrometeors. In this paper, a fuzzy-logic, C-POL hydrometeor classification algorithm following the method of Dolan et al. [46] is employed to carry out the hydrometeor classification of the Mei-Yu rainfall. Five hydrometeor types are identified as $\mathrm{IC}=$ ice crystals, GA = graupel, DS = dry snow, WS = wet snow, and $\mathrm{RN}=$ rain. The vertical cross sections of hydrometeor categories derived from C-POL along $284.0^{\circ}$ azimuth at 0925 BJT on 30 June 2018 and WRF simulations at the same position are shown in Figure 11. Due to limited C-POL datasets in this field campaign, the distributions of different hydrometers frequency are not shown in this study.

The middle and upper regions (above $6 \mathrm{~km}$ ) of the cross section from C-POL are characterized by dry snow and regions of ice crystals. Regions of graupel are concentrated at heights from 4 to $8 \mathrm{~km}$, which then transition to rain drops. For the vertical distribution of rain particles, all simulations are close to the observation, although SBU-YLIN scheme simulates greater top height of rain than the observation. The 


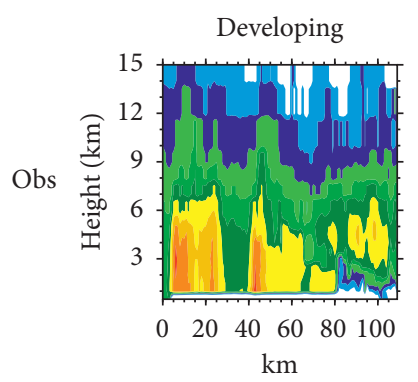

(a)

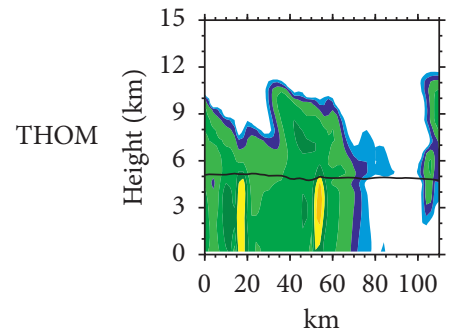

(d)

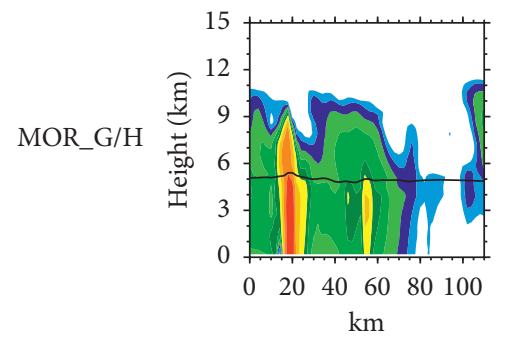

(g)

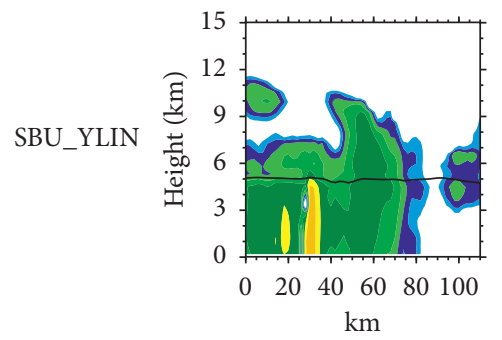

(j)

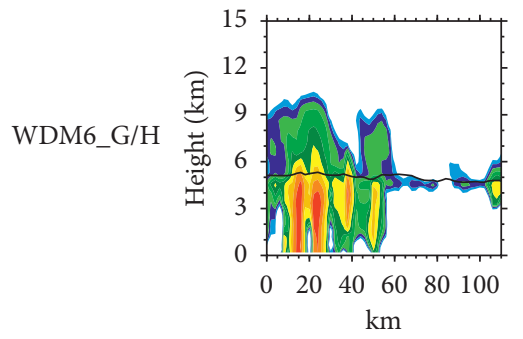

(m)

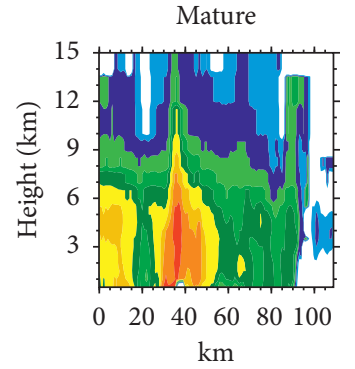

(b)

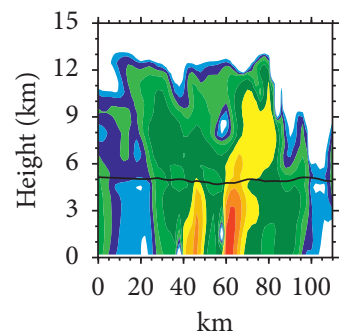

(e)

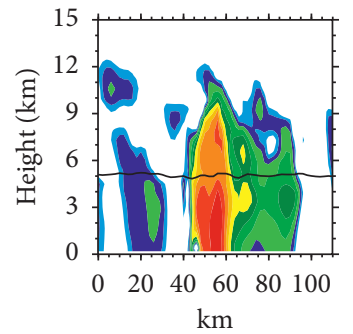

(h)

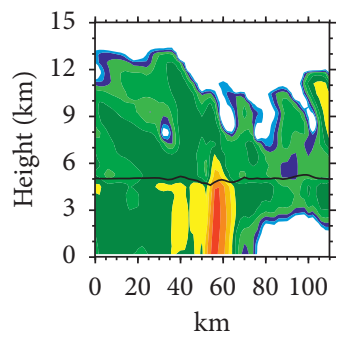

(k)

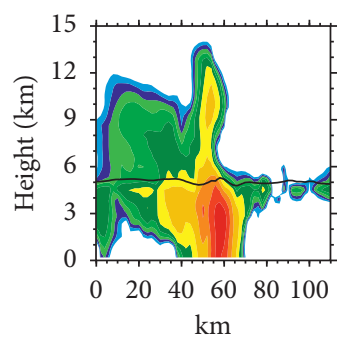

(n)

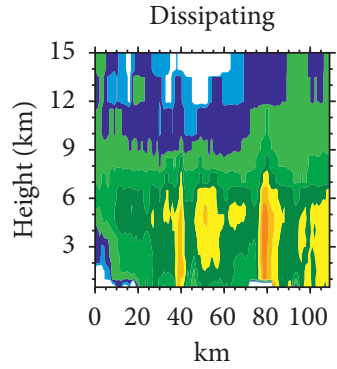

(c)

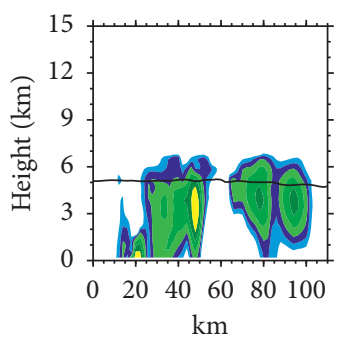

(dBZ)

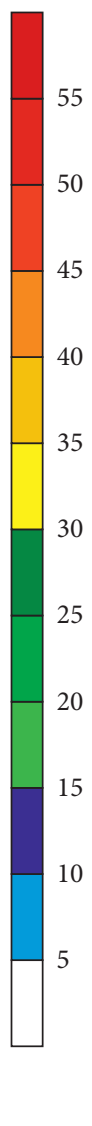

(1)

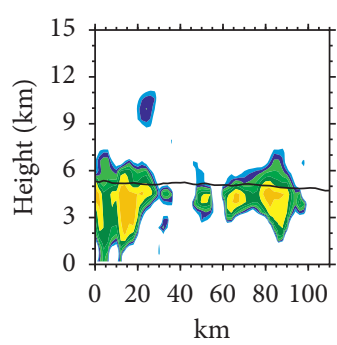

(o)

FIGURE 9: Cross section of radar reflectivity (in dBZ) along the black lines in Figure 7 from (a), (b), (c) observations and simulations of (d), (e), (f) THOM; (g), (h), (i) MOR_G/H; (j), (k), (l) SBU-YLIN; and (m), (n), (o) WDM6_G/H during developing (the first column), mature (the second column), and dissipating (the third column) stage. The black solid lines in simulations denote the $0^{\circ} \mathrm{C}$ isotherm.

four simulated vertical distributions of snow are also similar to the observation. However, there are many discrepancies found in the graupel and ice vertical distribution. THOM scheme simulates almost the same vertical graupel distribution as the observation, but fewer ice particles. MOR_G/H scheme simulates more graupel than observation. The 


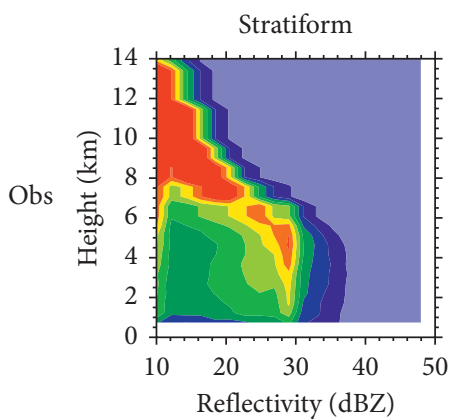

(a)

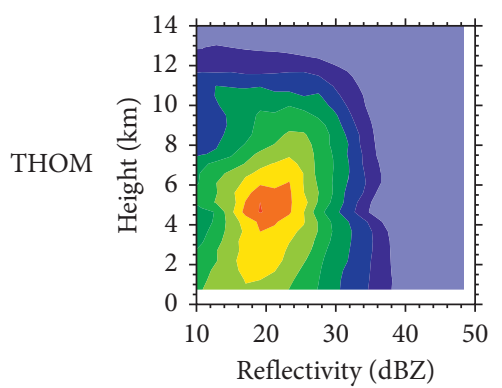

(c)

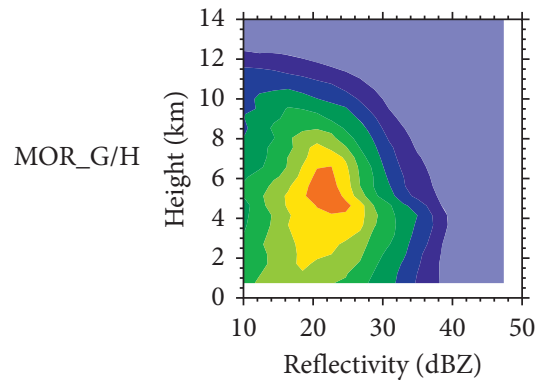

(e)

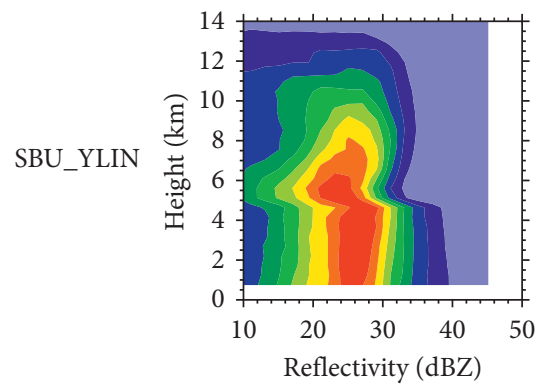

(g)

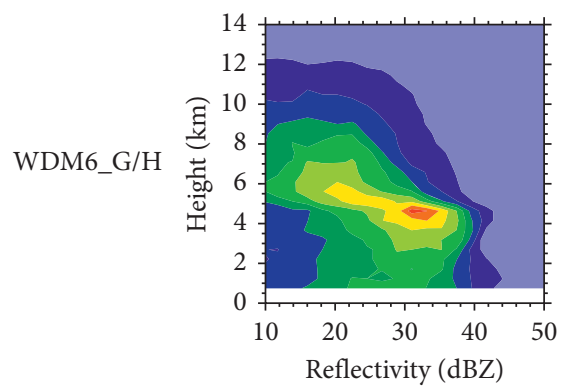

(i)

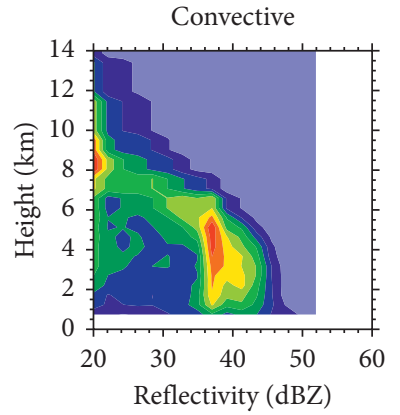

(b)

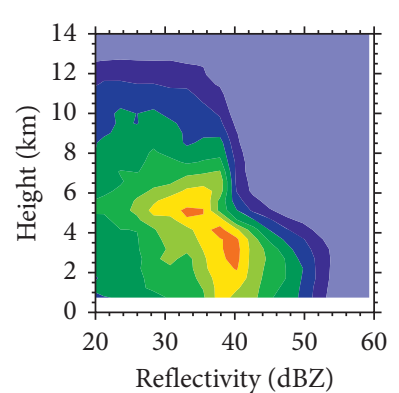

(d)

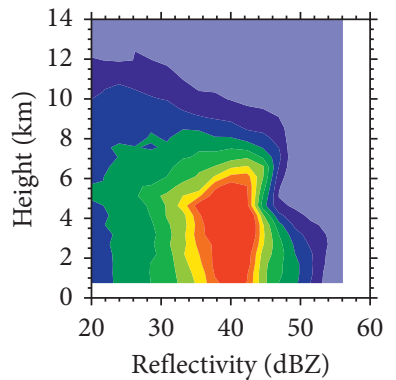

(f)

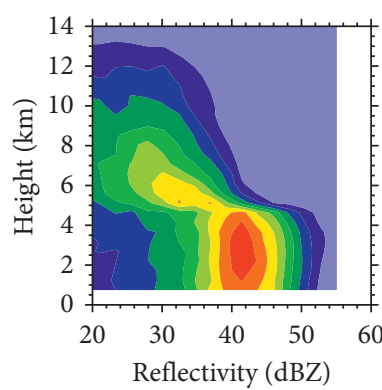

(h)

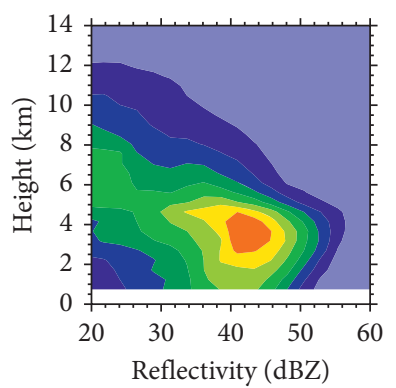

(j)
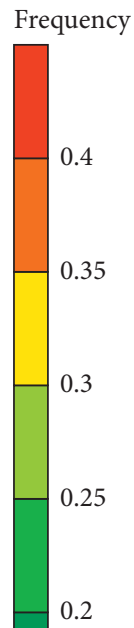

0.15

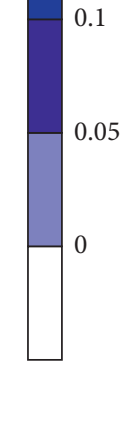

0.05

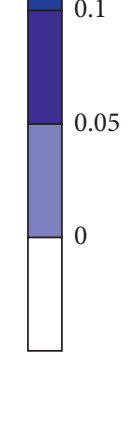




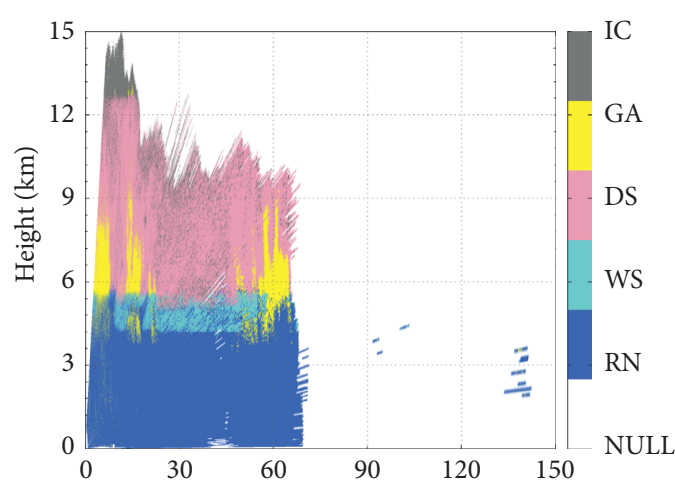

(a)

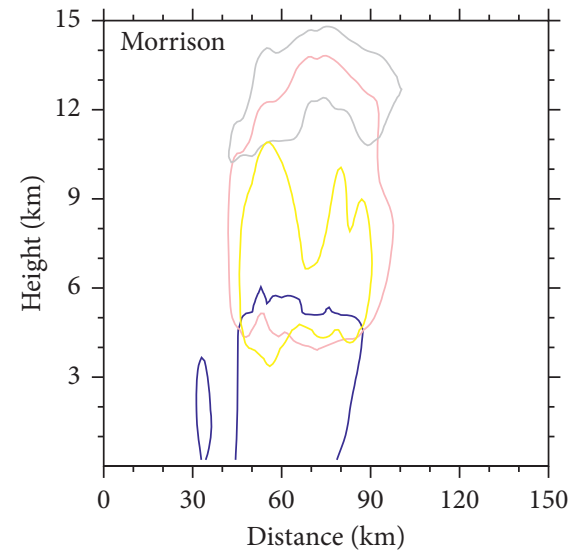

(c)

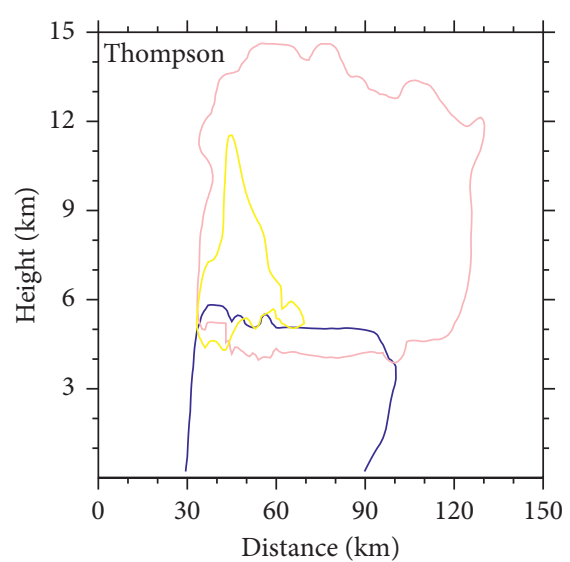

(b)

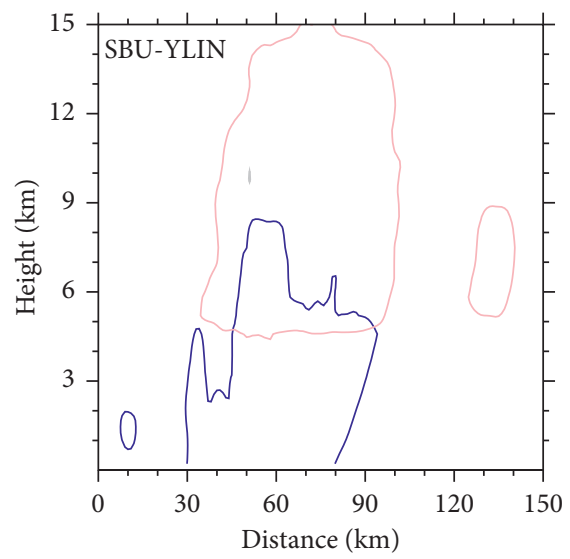

(d)

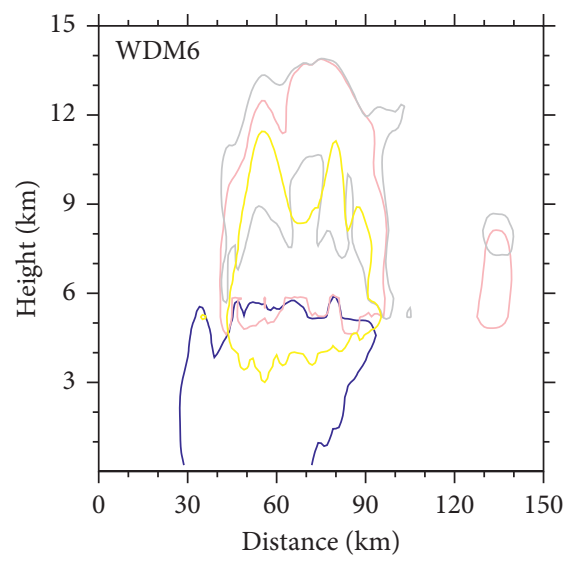

(e)

Figure 11: Vertical cross section of hydrometeor categories derived from C-POL along $284.0^{\circ}$ azimuth at 0925 LT on 30 June 2018 and simulations. HC categories are defined as IC $=$ ice crystals, GA = graupel, DS = dry snow, WS = wet snow, and RN = rain. For the simulations, the blue curve represents the area where the rain mixing ratio is positive, yellow line indicates graupel distribution, pink line represents snow distribution, and grey line represents ice distribution.

MOR_G/H and WDM6_G/H schemes simulate more graupel and ice than those in the observations. Because the SBU-YLIN scheme does not distinguish between graupel and snow, only the snow distribution is shown in Figure 11. Overall, the discrepancies between model output and observations exist in the midlevel to upper level (above $6 \mathrm{~km}$ ), which results from the inability of the model to accurately represent the particle size distribution, ice processes, and storm dynamics.

Similar to the method of analyzing clouds and precipitation, hydrometeor mixing ratio of stratiform and convective clouds is evaluated over the same study area. Figure 12 shows 


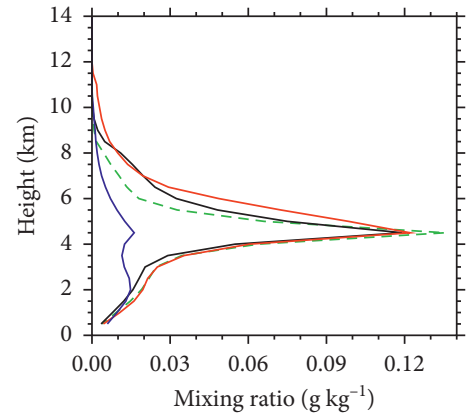

— WDM6_G/H - MOR_G/H

— SBU-YLIN _.. THOM

(a)

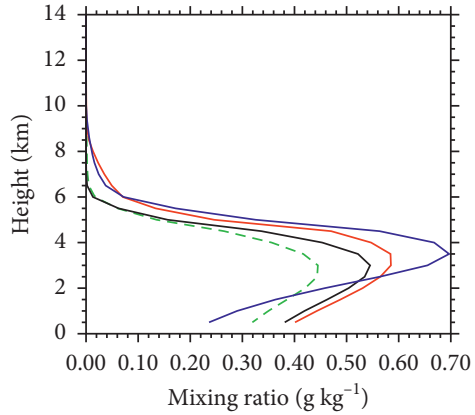

— WDM6_G/H - MOR_G/H

— SBU-YLIN _.. THOM

(d)

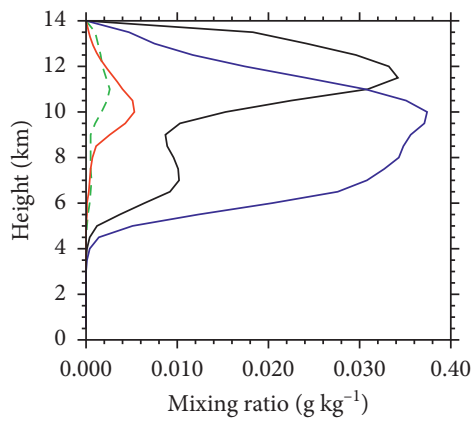

- WDM6_G/H - MOR_G/H

— SBU-YLIN _. . THOM

(g)

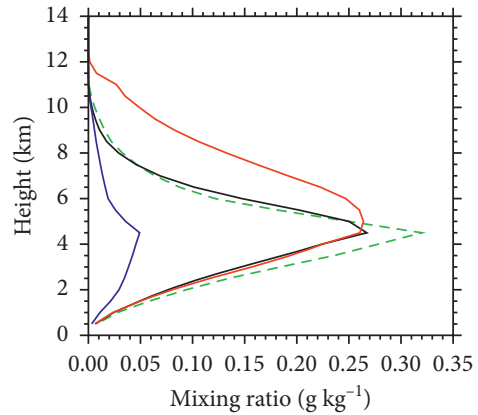

- WDM6_G/H - MOR_G/H

— SBU-YLIN - - THOM

(b)

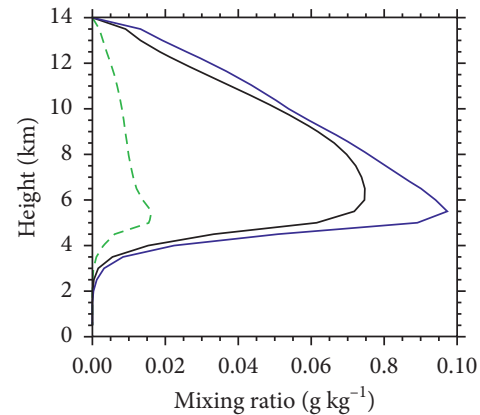

— WDM6_G/H - MOR_G/H

— SBU-YLIN _- - THOM

(e)

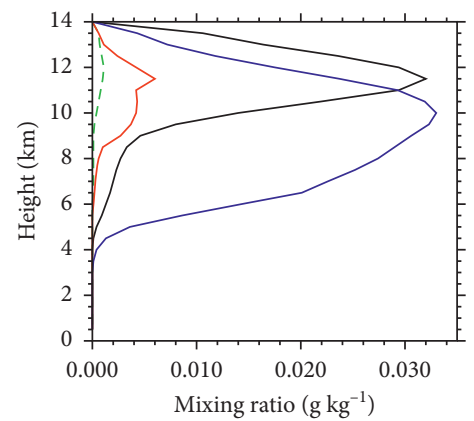

— WDM6_G/H - MOR_G/H

— SBU-YLIN _. . THOM

(h)

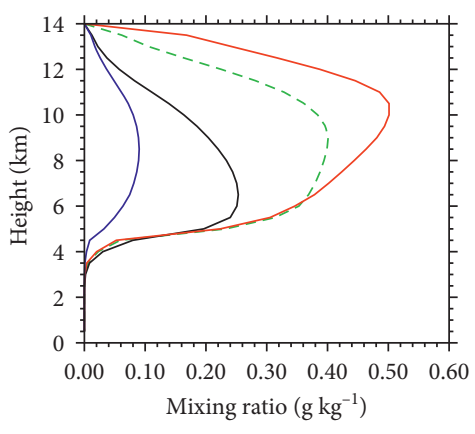

— WDM6_G/H - MOR_G/H

_ SBU-YLIN _.. THOM

(j)

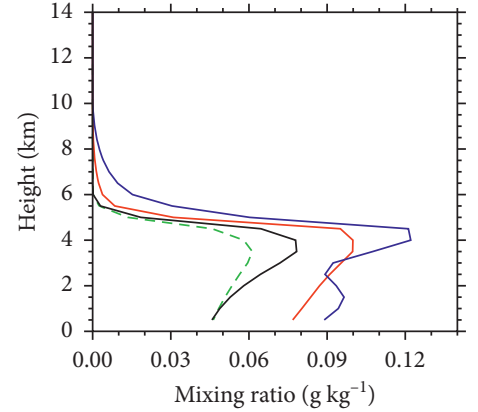

- WDM6_G/H - MOR_G/H

— SBU-YLIN -.. THOM

(c)

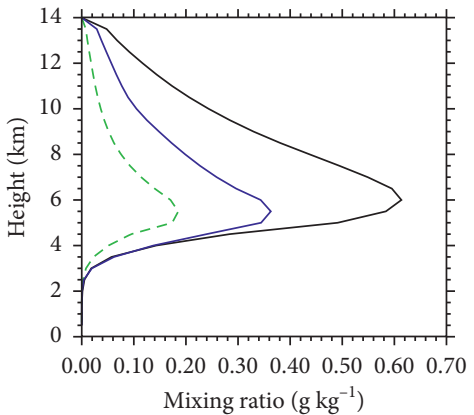

—WDM6_G/H - MOR_G/H

— SBU-YLIN _.. THOM

(f)

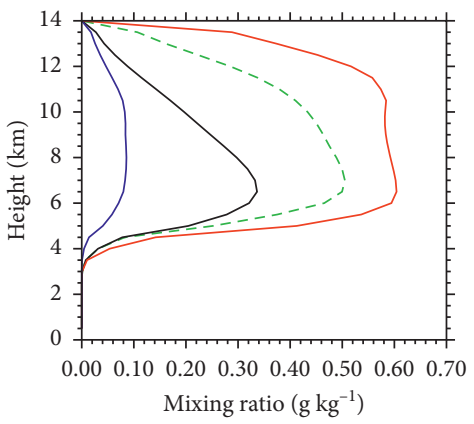

— WDM6_G/H - MOR_G/H

— SBU-YLIN _.. THOM

(i)

Figure 12: The time- and domain-averaged hydrometeor mixing ratio vertical profiles over the (a), (c), (e), (g), (i) stratiform and (b), (d), (f), (h), (j) convective regions for (a), (b) THOM; (c), (d) MOR_G/H; (e), (f) SBU-YLIN; and (g), (h) WDM6_G/H scheme from 0300 to 0500 $\mathrm{UTC}$ on 30 June 2018 within the region $\left(107-117^{\circ} \mathrm{E}, 27-35^{\circ} \mathrm{N}\right)$. 
TABLE 3: Temporally and domain-averaged integrated vertically mixing ratio of cloud, rain, and ice-phase hydrometeors (sum of ice, snow, and graupel) of the four microphysical schemes over stratiform and convective region.

\begin{tabular}{lccccc}
\hline & Cloud & $\begin{array}{c}\text { Stratiform } \\
\text { Rain }\end{array}$ & $\begin{array}{c}\text { Ice-phase } \\
\text { Mixing ratio }\left(\mathrm{g} \cdot \mathrm{kg}^{-1}\right)\end{array}$ & $\begin{array}{c}\text { Convective } \\
\text { Rain }\end{array}$ \\
\hline THOM & 0.483 & 0.497 & 5.803 & 2.181 & 3.630 \\
MOR_G/H & 0.515 & 0.584 & 4.197 & 1.974 & 4.393 \\
SBU-YLIN & 0.630 & 0.858 & 7.120 & 2.964 & 5.195 \\
WDM6_G/H & 0.257 & 1.037 & 2.651 & 0.428 & 5.166 \\
\hline
\end{tabular}

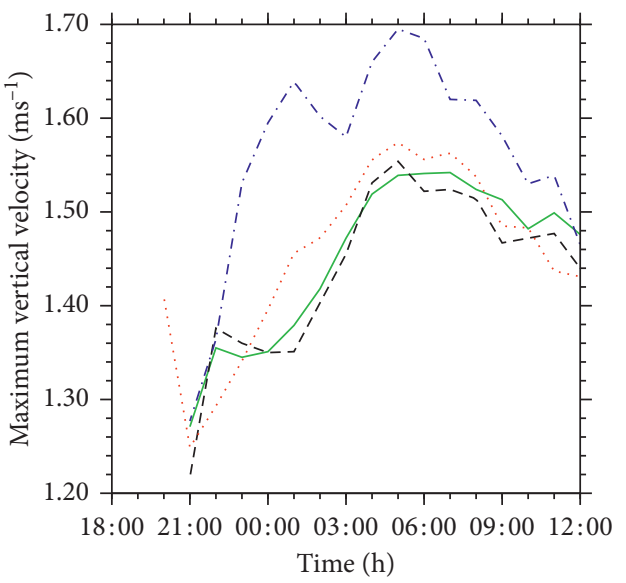

(a)

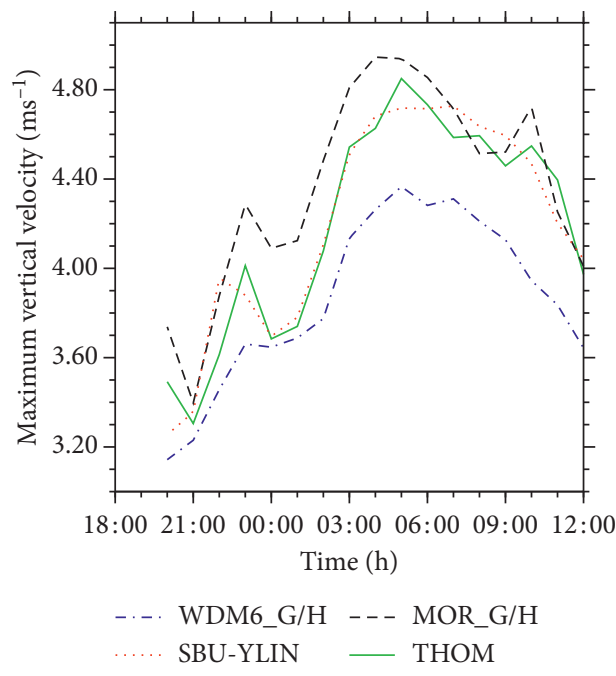

(b)

FIGURE 13: The temporal evolution of domain-averaged maximum vertical air velocity of THOM, MOR_G/H, SBU-YLIN, and WDM6_G/H scheme over (a) stratiform and (b) convective regions within the region $\left(107-117^{\circ} \mathrm{E}, 27-35^{\circ} \mathrm{N}\right)$.

the time- and domain-averaged hydrometeor mixing ratio vertical profiles over the stratiform and convective regions for different microphysical schemes. We can clearly find a common feature in different schemes: less cloud and rain are distributed in the stratiform region than in the convective region. Meanwhile, there are more snow and cloud ice particles distributed in the stratiform region than in the convective region, and less graupel is seen in the stratiform cloud regime than in the convective region. These features indicate that the convective-stratiform partitioning algorithm used in this paper is reasonable. Compared to the other three schemes, WDM6_G/H scheme produced less cloud in both cloud regions and more rain in stratiform region. In convective regions, more rain particles are also found above $2 \mathrm{~km}$ for WDM6_G/H scheme. This indicates a large autoconversion of cloud water to rain in the WDM6_G/H scheme than the other schemes. Table 3 shows integrated vertically mixing ratio of cloud, rain, and icephase hydrometeors which is the sum of ice, snow, and graupel over stratiform and convective regions. The icephased particles in the WDM6_G/H scheme are less than those in the other schemes especially for the snow particles in both cloud regimes. This is becuase the smallest maximum vertical air velocity of WDM6_G/H scheme in the convective regime, cloud, and rain particles cannot be brought to upper level air (Figure 13). The THOM and SBU-YLIN scheme simulate less ice but more snow than the other schemes, resulting in moderate mixing ratio of ice-phase particles. The MOR_G/H scheme simulates the most icephase particles in convective region, corresponding to the highest radar reflectivity within $0-6 \mathrm{~km}$ and the strongest maximum vertical velocity in convective region, while the mixing ratio of ice-phase particles in stratiform region shows a moderate level, and this is consistent with the underestimated reflectivity above $6 \mathrm{~km}$.

\section{Conclusions}

Based on multisource datasets from IMFRE 2018, four bulk cloud microphysics schemes in WRF model were evaluated with respect to their ability to simulate convective and stratiform precipitation, structure, and cloud microphysical properties for a Mei-Yu front rainstorm. The findings from this study can be summarized as follows.

In spite of minor location errors for the accumulated rainfall as compared with the observations, all simulations captured the distribution of northwest-southeast oriented rain bands. However, four schemes underestimate the total precipitation by $23 \%-35 \%$, and this is mainly attributed to the underestimation of stratiform precipitation. We also found that THOM, MOR_G/H, and SBU-YLIN scheme underestimate the stratiform precipitation and overestimate 
the convective rain, while WDM6_G/H scheme produces less convective precipitation than observation.

THOM, MOR_G/H, and SBU-YLIN schemes can successfully capture the horizontal evolution of MCSs during the whole life cycle, but there is a time delay for about 1-2 hours. For the vertical distribution of radar reflectivity, the large reflectivity ( $>40 \mathrm{dBZ}$ ) within the deep convective cores from radar extended to about $6 \mathrm{~km}$ at the developing stage. The simulated heights of deep convective cores are close to observations except for MOR_G/H scheme with the large reflectivity extending to about $9 \mathrm{~km}$. At the mature stage, deep convective cores of THOM and WDM6_G/H schemes extended to about $12 \mathrm{~km}$ which is almost the same distance that occurred in radar observations. However, all simulations underestimate radar reflectivity in the stratiform region at heights of $9-13 \mathrm{~km}$ during the whole lifetime of MCSs.

Discrepancies in the vertical distribution characteristics between simulations and observations are obvious form the CFADs of reflectivity. For stratiform cloud, all simulated radar reflectivity values at upper levels $(8-14 \mathrm{~km})$ are smaller than the observations. For convective cloud, the observed maximum probability at middle and lower levels $(0-6 \mathrm{~km})$ is located around 35-40 dBZ, and the simulations of THOM and SBU-YLIN are as much as the observations. The simulated radar reflectivity of MOR_G/H is stronger than other schemes. Simulations of reflectivity above $6 \mathrm{~km}$ are much weaker than the observations.

All schemes are able to simulate well the rain distribution at low level and snow distribution above $6 \mathrm{~km}$. However, there are many discrepancies between simulations and observation of graupel and ice vertical distribution. THOM and SBUYLIN scheme simulate less ice but more snow than other schemes, resulting in moderate mixing ratio of ice-phase particles. The MOR_G/H scheme simulates the most icephase particles in convective region, corresponding to the strongest maximum vertical velocity in convective region, while the ice-phase particles in stratiform region show a moderate level, and this is consistent with the underestimated reflectivity above $6 \mathrm{~km}$. The ice-phased particles in WDM6_G/H scheme are less than those in other schemes especially for the snow particles in both cloud regimes.

In summary, each bulk scheme evaluated in this study has its advantages and shortcomings for different cloud regimes. Overall, the discrepancies between model output and observations mostly exist in the midlevel to upper level, which probably results from the inability of the model to accurately represent the particle size distribution, ice processes, and storm dynamics. Therefore, more detailed microphysics schemes, such as higher moment schemes or complicated schemes that can describe more ice-phase particle interactions, may be needed to properly represent these evaluated features.

It is worth noting that, due to the limited Mei-Yu front rainstorm cases observed by IMFRE, the microphysical characteristics of Mei-Yu rainfall will continue to be observed and studied in the later stage. Further observations from major field campaigns and simulations are still necessary. Meanwhile, the errors caused by the nonlinear method of the numerical sensitivity test, the uncertainties of model initials, and the limited ability of the model simulations (e.g., cumulus, land surface, or radiation schemes) all have certain influence on the simulation results.

\section{Data Availability}

The ERA-5 data are available at https://www.ecmwf.int/en/ forecasts/datasets/reanalysis-datasets/era5.

\section{Conflicts of Interest}

The authors declare that there are no conflicts of interest regarding the publication of this paper.

\section{Acknowledgments}

The authors would like to acknowledge China Meteorological Administration for providing the hourly precipitation data. This research was funded by the National Key R\&D Program of China (2018YFC1507200) and the National Natural Science Foundation of China under grants 41620104009, 41830965, and 41705034.

\section{References}

[1] D. Rosenfeld, "Aerosol-cloud interactions control of Earth radiation and latent heat release budgets," Space Science Reviews, vol. 125, no. 1-4, pp. 149-157, 2006.

[2] H. Morrison, G. Thompson, and V. Tatarskii, "Impact of cloudmicrophysics on the development of trailing stratiform precipitation in a simulated squall line: comparison of oneand two-moment schemes," Monthly Weather Review, vol. 137, no. 3, pp. 991-1007, 2009.

[3] Y.-L. Lin, R. D. Farley, and H. D. Orville, "Bulk parameterization of the snow field in a cloud model," Journal of Climate and Applied Meteorology, vol. 22, no. 6, pp. 1065-1092, 1983.

[4] S. A. Rutledge and P. V. Hobbs, "The mesoscale and microscale structure and organization of clouds and precipitation in midlatitude cyclones. Part XII: a diagnostic modeling study of precipitation development in narrow cloud-frontal rainbands," Journal of the Atmospheric Sciences, vol. 41, no. 20, pp. 2949-2972, 1984.

[5] M. P. Meyers, P. J. DeMott, and W. R. Cotton, "New primary ice-nucleation parameterization in an explicit cloud model," Journal of Applied Meteorology, vol. 31, no. 7, pp. 708-721, 1992.

[6] G. Thompson, P. R. Field, R. M. Rasmussen, and W. D. Hall, "Explicit forecasts of winter precipitation using an improved bulk microphysics scheme. Part II: implementation of a new snow parameterization," Monthly Weather Review, vol. 136, no. 12, pp. 5095-5115, 2008.

[7] H. Morrison and A. Gettelman, "A new two-moment bulk stratiform cloud microphysics scheme in the community atmosphere model, version 3 (CAM3). Part I: description and numerical tests," Journal of Climate, vol. 21, no. 15, pp. 3642-3659, 2008.

[8] K.-S. S. Lim and S.-Y. Hong, "Development of an effective double moment cloud microphysics scheme with prognostic cloud condensation nuclei (CCN) for weather and climate models," Monthly Weather Review, vol. 138, no. 5, pp. 1587-1612, 2010. 
[9] M. McCumber, W.-K. Tao, J. Simpson, R. Penc, and S.-T. Soong, "Comparison of ice-phase microphysical parameterization schemes using numerical simulations of tropical convection," Journal of Applied Meteorology, vol. 30, no. 7, pp. 985-1004, 1991.

[10] Y. Luo, Y. Wang, H. Wang, Y. Zheng, and H. Morrison, "Modeling convective-stratiform precipitation processes on a Mei-Yu front with the weather research and forecasting model: comparison with observations and sensitivity to cloud microphysics parameterizations," Journal of Geophysical Research, vol. 115, no. D18, p. D18117, 2010.

[11] Y. Luo, H. Wang, R. Zhang, W. Qian, and Z. Luo, "Comparison of rainfall characteristics and convective properties of monsoon precipitation systems over south China and Yangtze and Huai River Basin," Journal of Climate, vol. 26, no. 1, pp. 110-132, 2013.

[12] K. Suzuki, G. Stephens, A. Bodas-Salcedo et al., "Evaluation of the warm rain formation process in global models with satellite observations," Journal of the Atmospheric Sciences, vol. 72, no. 10, pp. 3996-4014, 2015.

[13] T. Michibata and T. Takemura, "Evaluation of autoconversion schemes in a single model framework with satellite observations," Journal of Geophysical Research: Atmospheres, vol. 120, no. 18, pp. 9570-9590, 2015.

[14] H.-J. Song and B.-J. Sohn, "An evaluation of WRF microphysics schemes for simulating the warm-type heavy rain over the Korean Peninsula," Asia-Pacific Journal of Atmospheric Sciences, vol. 54, no. 2, pp. 225-236, 2018.

[15] H. Morrison and J. A. Milbrandt, "Parameterization of cloud microphysics based on the prediction of bulk ice particle properties. Part I: scheme description and idealized tests," Journal of the Atmospheric Sciences, vol. 72, no. 1, pp. 287-311, 2015.

[16] B. J. Putnam, M. Xue, Y. Jung, G. Zhang, and F. Kong, "Simulation of polarimetric radar variables from 2013 CAPS spring experiment storm-scale ensemble forecasts and evaluation of microphysics schemes," Monthly Weather Review, vol. 145, no. 1, pp. 49-73, 2017.

[17] K. Sassen, Z. Wang, and D. Liu, "Global distribution of cirrus clouds from CloudSat/Cloud-Aerosol Lidar and Infrared Pathfinder Satellite Observations (CALIPSO) measurements," Journal of Geophysical Research, vol. 113, Article ID D00A12, 2008.

[18] H. Chepfer, S. Bony, D. Winker, M. Chiriaco, J.-L. Dufresne, and G. Sèze, "Use of CALIPSO lidar observations to evaluate the cloudiness simulated by a climate model," Geophysical Research Letters, vol. 35, no. 15, p. L15704, 2008.

[19] K.-H. Min, S. Choo, D. Lee, and G. Lee, "Evaluation of WRF cloud microphysics schemes using radar observations," Weather and Forecasting, vol. 30, no. 6, pp. 1571-1589, 2015.

[20] J. S. Kain, S. J. Weiss, D. R. Bright et al., "Some practical considerations regarding horizontal resolution in the first generation of operational convection-allowing NWP," Weather and Forecasting, vol. 23, no. 5, pp. 931-952, 2008.

[21] N. M. Hitchens, M. E. Baldwin, and R. J. Trapp, “An objectoriented characterization of extreme precipitation-producing convective systems in the midwestern United States," Monthly Weather Review, vol. 140, no. 4, pp. 1356-1366, 2012.

[22] M. Johnson, Y. Jung, D. T. Dawson II, and M. Xue, "Comparison of simulated polarimetric signatures in idealized supercell storms using two-moment bulk microphysics schemes in WRF," Monthly Weather Review, vol. 144, no. 3, pp. 971-996, 2016.
[23] J. Rémillard, A. M. Fridlind, A. S. Ackerman et al., "Use of cloud radar Doppler spectra to evaluate stratocumulus drizzle size distributions in large-eddy simulations with size-resolved microphysics," Journal of Applied Meteorology and Climatology, vol. 56, no. 12, pp. 3263-3283, 2017.

[24] A. R. Naeger, B. A. Colle, and A. Molthan, "Evaluation of cloud microphysical schemes for a warm frontal snowband during the GPM Cold Season Precipitation Experiment (GCPEx) Mon," Monthly Weather Review, vol. 145, no. 11, pp. 4627-4650, 2017.

[25] M. Taufour, B. Vié, C. Augros et al., "Evaluation of the twomoment scheme LIMA based on microphysical observations from the HyMeX campaign," Quarterly Journal of the Royal Meteorological Society, vol. 144, no. 714, pp. 1398-1414, 2018.

[26] Y. Ding, Monsoons over China, Kluwer Academic Publishers, Dordrecht, Netherlands, 1994.

[27] Y. Hu, Y. Deng, Z. Zhou, C. Cui, and X. Dong, “A statistical and dynamical characterization of large-scale circulation patterns associated with summer extreme precipitation over the middle reaches of Yangtze river," Climate Dynamics, vol. 52, no. 9-10, pp. 6213-6228, 2019.

[28] S.-J. Chen, Y.-H. Kuo, W. Wang, Z.-Y. Tao, and B. Cui, “A modeling case study of heavy rainstorms along the Mei-Yu front," Monthly Weather Review, vol. 126, no. 9, pp. 23302351, 1998.

[29] D. D. Churchill and R. A. Houze, "Development and structure of winter monsoon cloud clusters on 10 December 1978," Journal of the Atmospheric Sciences, vol. 41, no. 6, pp. 933-960, 1984.

[30] W.-K. Tao, J. Simpson, and M. McCumber, "An ice-water saturation adjustment," Monthly Weather Review, vol. 117, no. 1, pp. 231-235, 1989.

[31] W.-K. Tao, X. Li, A. Khain et al., "Role of atmospheric aerosol concentration on deep convective precipitation: cloud-resolving model simulations," Journal of Geophysical Research, vol. 112, no. D24, Article ID D24S18, 2007.

[32] Y. Shen, Y. Pan, J. Yu et al., "Quality assessment of hourly merged precipitation product over China," Journal of Atmospheric Sciences, vol. 36, no. 1, pp. 37-46, 2013, in Chinese.

[33] R. J. Joyce, J. E. Janowiak, P. A. Arkin, and P. Xie, "CMORPH: a method that produces global precipitation estimates from passive microwave and infrared data at high spatial and temporal resolution," Journal of Hydrometeorology, vol. 5, no. 3, pp. 487-503, 2004.

[34] H. Hersbach and D. Dee, ERA5 Reanalysis is in Production, ECMWF Newsletter 147, ECMWF, Reading, UK 2016.

[35] T. Wu, Y. Wan, W. Wo, and L. Leng, "Design and application of radar reflectivity quality control algorithm in SWAN," Meteorological Science and Technology, vol. 41, pp. 809-817, 2013, in Chinese.

[36] Y. Xiao, Y. Wan, J. Wang, B. Wang, and Z. Wang, "Study of an automated Doppler radar velocity dealiasing algorithm," Plateau Meteorology, vol. 31, pp. 1119-1128, 2012, in Chinese.

[37] B. Wang, L. Leng, and W. Zhang, "Analysis of detection characteristics of a C-Band Polarimetric Radar for an Intense Convective Precipitation case," in Proceedings of the International Workshop on High Impact Weather Research, Ningbo, China, January 2015, in Chinese.

[38] Y. Lin and B. A. Colle, "A new bulk microphysical scheme that includes riming intensity and temperature-dependent ice characteristics," Monthly Weather Review, vol. 139, no. 3, pp. 1013-1035, 2011. 
[39] S.-Y. Hong, Y. Noh, and J. Dudhia, "A new vertical diffusion package with an explicit treatment of entrainment processes," Monthly Weather Review, vol. 134, no. 9, pp. 2318-2341, 2006.

[40] M. J. Iacono, J. S. Delamere, E. J. Mlawer et al., "Radiative forcing by long-lived greenhouse gases: calculations with the AER radiative transfer models," Journal of Geophysical Research, vol. 113, no. D13, p. D13103, 2008.

[41] M. D. Chou and M. J. Suarez, "An efficient thermal infrared radiation parameterization for use in general circulation models," Report, vol. 85, 1994.

[42] F. Chen and J. Dudhia, "Coupling an advanced land-surface/ hydrology model with the Penn State/NCAR MM5 modeling system. Part I: model description and implementation," Monthly Weather Review, vol. 129, no. 4, pp. 569-585, 2001.

[43] M. Steiner, R. A. Houze Jr., and S. E. Yuter, "Climatological characterization of three-dimensional storm structure from operational radar and rain gauge data," Journal of Applied Meteorology and Climatology, vol. 34, 1995.

[44] Z. Feng, X. Dong, B. Xi et al., "Top-of-atmosphere radiation budget of convective core/stratiform rain and anvil clouds from deep convective systems," Journal of Geophysical Research: Atmospheres, vol. 116, no. D23, 2011.

[45] P. L. Smith, "Equivalent radar reflectivity factors for snow and ice particles," Journal of Climate and Applied Meteorology, vol. 23, no. 8, pp. 1258-1260, 1984.

[46] B. Dolan, S. A. Rutledge, S. Lim, V. Chandrasekar, and M. Thurai, "A robust C-band hydrometeor identification algorithm and application to a long-term polarimetric radar dataset," Journal of Applied Meteorology and Climatology, vol. 52, no. 9, pp. 2162-2186, 2013. 